\title{
Identificación nacional mediante la defensa del idioma: El caso de Puerto Rico
}

\author{
IsidRo SEPÚlvedA MuÑoz
}

Desde la consolidación institucional de las naciones como estados se han mantenido unos objetivos esenciales mínimos que basaran la determinación de un «imaginario colectivo" en los miembros de la nación como "comunidad". Si Kedourie señalaba como trípode del nacionalismo alemán del siglo XIX la raza, la historia y la cultura, otros autores han señalado los mismos elementos operantes durante la revolución francesa, especialmente durante su período jacobino '. En las postrimerias del siglo $x x$ - cuando el futuro de los nacionalismos era profetizado como declinante, incluso por los analistas más cuidadosos de la ideología ${ }^{2}$-, han incidido un conjunto de fenómenos que potencian la eclosión de conflictos nacio. nalistas, susientados por grupos muy minoritarios hasta finales de la década de los ochenta.

Independientemente de la determinación de una comunidad nacional de aspirar a la institucionalización de su conjunto en un estado o a la permanencia dentro de un estado multinacional, su proyección exterior como nación persigue los mismos objetivos: "dominio del territorio, control de las condiciones materiales de existencia, defensa de la identidad y autodeterminación cultural» ${ }^{3}$.

1 Kedourie, E., Nacionalism. Londres, Hutchinson, 1966. Jouvenel, B. D., Los origenes del Estado moderno. Madrid, Emesa, 1977. Briton, C., Los jacobinos. Buenos Aires. Huemel, 1962.

2 Hobsbawn. E. J., Naciones y nacionalismo desde 1780. Barcelona, Crítica, 1991. Gellner, E. Cultura, identidad y politica. El nacionalismo y los nuevos cambios sociales. Barcelona, Gedisa, 1989.

3 Acosta Sánchez, J., "Los presupuestos teóricos del nacionalismo y el nuevo ciclo del fenómeno", Revista de Estudios Politicos 77, julio-septiembre de 1992, pág. 119. 
Puerto Rico constituye un caso especialmente significativo en el estudio de los objetivos esenciales de defensa nacionalista. Con una soberanía nacional limitada, buena parte de su territorio utilizado como bases militares estadounidenses y una economía totalmente dependiente del continente, la identidad nacional ha encontrado en la defensa de su tradición cultural y de su idioma el elemento fundamental de autodeterminación.

\section{LA BATALLA DEL IDIOMA}

En abril de 1991 el Partido Popular Democrático (PPD) derogó la Ley de Idiomas Oficiales, dictada en 1902, que aseguraba al inglés una igualdad jurídica, educativa y política respecto al idioma español en Puerto Rico. En el atardecer del 21 de enero de 1993, mientras en el interior del Capitolio la mayoría estadista del Partido Nuevo Progresista (PNP) aprobaba una ley que elevaba al inglés a lengua oficial del estado, en el exterior una gran concentración reclamaba entre gritos de protesta y cánticos festivos la preeminencia del español como única lengua estatal. Ambos actos sintetizaban la división existente en la isla: dos políticas, dos idiomas, dos identidades.

Esta escisión puertorriqueña no deviene de una política puntual generada por el ex-Gobernador Hernández Colón, ni por la estrategia de réplica por parte del PNP que llevó a La Fortaleza a su candidato, Pedro Rosselló. Esta división tiene más de un siglo de antigüedad y fue definitiva y dramáticamente significada durante las primeras administraciones estadounidenses. En la actualidad se manifiesta en toda su crudeza pues se acerca la hora en que el pueblo de Puerto Rico debe decidir (en realidad por primera vez en su historia) su propio futuro. $Y$ en esta decisión el idioma es a la vez «símbolo» e «instrumento" de los opuestos proyectos de futuro.

La guerra hispano-estadounidense de 1898 y la firma del Tratado de París del mismo año tuvo como una de sus consecuencias el paso a manos estadounidenses del gobierno de la isla de Puerto Rico; durante todo ese año había existido un régimen autonómico que había llevado a la creación de un parlamento legislativo y un gobierno propio. A partir de ese momento se generó la singularidad de Puerto Rico en el ámbito americano: pertenencia a Estados Unidos y pervivencia de la herencia cultural española en la isla. Dado que dicha continuidad sufrió la presión estadounidense, la pervivencia no se ha mantenido sino mediante una defensa activa de la identidad cultural e histórica. Identidad que se encuentra a caballo entre la herencia histórica y cultural de tradición hispana y la atracción de la pujante economía estadounidense y el american way of 
life. Esta confrontación se encuentra inscrita a su vez en un más amplio movimiento que abarca a toda la América de cultura ibero-americana. Movimiento que si bien encontró cierta plataforma de configuración en torno al pan-americanismo de finales del siglo xIX, la hegemonía y dirigismo en que cayó la Unión Panamericana y la posterior Organización de Estados Americanos por parte de Estados Unidos propició la generación de movimientos indepedientes integrando componentes latinoamericanos en exclusiva. Pertenencia a Estados Unidos, tradición cultural hispana e identidad latinoamericana conforman el trípode sustentador de la nacionalidad puertorriqueña y determinan su singularidad, siendo por tanto su estudio especialmente importante ante la actual situación internacional y la actual conformación de grandes bloques transnacionales.

La "batalla del idioma» se ha mantenido a lo largo del siglo, desde el mismo momento de la toma de posesión por Estados Unidos de la isla. No se comprende sino dentro de una larga marcha de Puerto Rico hacia su autodeterminación y la preservación de su cultura como identificadora de un pueblo; con vocación por tanto de constituirse, a largo o corto plazo, en un Estado independiente. ¿Cómo superó Puerto Rico la presión llevada a cabo por Estados Unidos para "americanizar" la isla con el fin de conseguir una más rápida y mayor integración de su sociedad con la de la Unión? ¿Por qué ha sido tomado el idioma como "símbolo" de esa defensa de la identidad puertorriqueña, hasta llegar a decirse que "ser puertorriqueño es una cuestión de idioma»? ${ }^{4}$. He aqui algunas respuestas a estas interrogantes.

\section{LOS PLANTEAMIENTOS DE POLITICA EXTERIOR ESTADOUNIDENSE ANTE LA ENCRUCIJADA DE 1898}

La superación de los problemas causados por la guerra de secesión supuso para las elites dirigentes de Washington la vuelta a una de las constantes de su política interior, estrechamente enlazada con la exterior: el crecimiento territorial como necesidad de estabilidad y desarrollo. Pero las características de la política anterior (expansión territorial e incorporación continuista a la Unión) no podían mantenerse de modo efectivo

" «Ser puertorriqueño es una cuestión de idioma, pues nuestra lengua nacional es ingrediente consustancial e indispensable de la cultura puertorriqueña". La frase pertenece a uno de los últimos eslabones de la larga y en algunos momentos heroica cadena de defensores puertorriqueños del idioma español; DELGAdo Citrón, C., Problemas juridicos y constitucionales del idioma español en Puerto Rico. San Juan. Revista del Colegio de Abogados de Puerto Rico (RCAPR), 1990, pág. 5. 
ante la firma con Londres de un tratado de límites con la Columbia Británica y por la población de las fronteras y la estabilidad política mexicanas. En consecuencia se desarrolló un doble programa de actuación; una continuidad de la expansión, pero rompiendo el criterio de continuidad territorial, y la articulación de un programa de política exterior exclusivamente americano: el panamericanismo. En ambos se encontraban armonizados idealmente cuatro elementos hasta cierto punto antagónicos: comercio, geopolítica, racismo y mesianismo, apoyado cada uno en su posterior.

La sociedad y la economía estadounidense habían adquirido un gran desarrollo en el último tercio del siglo xix. Desde el término de la guerra de secesión hasta el inicio de la Primera Guerra Mundial la población se había triplicado; la producción agraria en los últimos treinta años de siglo se dobló y antes de la guerra mundial se cuadruplicó con respecto a 1900. Todo ello había producido unos excedentes y una acumulación de capital que no podían ser colocados en el interior del país, por lo que se debian buscar fuera los mejores lugares para hacerlos productivos.

En cuanto al planteamiento geoestratégico, ya en 1890 un importante teórico de la política exterior estadounidense, Alfred Thayer Mahan, anunciaba la necesidad imperiosa de adquirir bases estratégicas en el Caribe y el Pacífico para afianzar y extender el control de Estados Unidos en todo el hemisferio ${ }^{5}$. La búsqueda de esos lugares dio lugar al diseño de una nueva concepción en la expansión territorial y, sobre todo, a una nueva práctica de política exterior. El objetivo final, a diferencia de to perseguido hasta la guerra de secesión, no era la expansión territorial anexionista; a partir de la formulación del panamericanismo el objetivo fue el control indirecto y su área principal el ámbito del Caribe y el $\mathrm{Pa}$ cífico. Para fraguar este territorio de implantación Estados Unidos llevó a cabo dos actuaciones que variaron profundamente la geoestrategia de la zona: la guerra hispano-estadounidense (1898) y la independencia de $\mathrm{Pa}$ namá (1903).

La coyuntura internacional finisecular cambió definitivamente la política exterior estadounidense. 1898 fue el año decisivo. En julio la Unión se anexionó el archipiélago de Hawaii y en septiembre decretó la política de "puertas abiertas" en China; en diciembre, con la firma del tratado de París, la soberanía de las islas Filipinas y Guam pasaban de manos españolas a estadounidenses, mientras Cuba y Puerto Rico recaían bajo su

\footnotetext{
${ }^{5}$ Pratt, J., America's Colonial Experiment. Nueva York. Prentice Hall Inc., 1950, pág. 26.
} 
dependencia directa. Con esta actuación Estados Unidos consiguió el control efectivo del Caribe y, en consecuencia, la comunicación directa entre ambas zonas necesitaba inaplazablemente un canal interoceánico bajo la misma soberanía.

Mediante la segunda medida (instigación y apoyo a la independencia panameña y soberanía sobre el territorio donde se construyera el canal) ratificaba ese control, encontraba el paso que comunicara ambas costas oceánicas y dejaba bajo su influencia directa toda Centroamérica, demarcando una nueva zona de expansión, no ya territorial sino económica. Mediante el Tratado Hay-Bunau Varilla (que los compromisarios panameños conocieron cuando ya estaba firmado y ante quienes no se tuvo la molestia de extender una copia en castellano) se otorgaba una franja de territorio para la construcción de un canal cuya explotación se concedía a perpetuidad a Estados Unidos. En agradecimiento a tales concesiones la Unión se comprometía a defender a Panamá de cualquier agresión extranjera. Este protectorado, apenas camuflado, tenía en el artículo VII del tratado su ratificación: Estados Unidos se irrogaba la posibilidad de intervenir en los asuntos internos panameños siempre que a su juicio peligrara la ley y el orden. Como en Cuba, esta segunda enmienda Platt trastocaba la independencia de un nuevo estado soberano en un protectorado estadounidense.

Finalmente, toda esa expansión se encontraba bajo la cobertura ideológica del destino manifiesto y del racismo cientificista, operativos en la política exterior norteamericana no sólo en lo referente a América sino en sus contactos con el resto del mundo. Mediante ellos Estados Unidos se contemplaba a sí mismo como el paradigma de la perfección política a que había llegado el hombre; dada la natural generosidad de sus ciudadanos, su condición les empujaba a exportar su sistema político, indisolublemente unido a su concepción de la vida y por tanto a sus productos comerciales. El diplomático, el militar y el comerciante estadounidenses se veían desde este prisma como misioneros de una causa nacional cuya validez era entendida como universal. Hay pocos párrafos que ilustren tan bien esta concepción como las palabras del senador Beveridge:

«El comercio del mundo ha de ser y será nuestro; con nuestra marina mercante abarcaremos el mundo. Hemos de construir una flota de guerra que corresponda a nuestra grandeza; nuestras instituciones volarán tras nuestros negocios. Una ley norteamericana, una civilización norteamericana, y una bandera norteamericana serán llevadas a tierras hasta ahora 
ensangrentadas y tenebrosas, que entonces serán iluminadas y embellecidas por esas instituciones de Dios" ${ }^{6}$.

Pero el dominio económico no era tan fácilmente exportable a otras naciones, máxime cuando éstas no contemplaban con tan buenos ojos las ventajas de la ley, la civilización y la bandera estadounidense ensalzadas por el senador Beveridge. Fue debido a esta resistencia que la doctrina Monroe, ya dentro del marco del panamericanismo, debió sufrir una nueva reinterpretación. Ésta se vio explicitada con el rechazo hecho por el Departamento de Estado a la doctrina Dragó, que negaba el derecho a recurrir a las armas para el cobro de la deuda externa. En contraposición a la tesis mantenida por el ministro de Relaciones Exteriores argentino, el presidente estadounidense dio a conocer lo que fue llamado "corolario Roosevelt» a la doctrina Monroe:

«El desorden en cualquier país obliga a la intervención de los Estados civilizados, en el entendido de que, en el hemisferio occidental, la adhesión de los Estados Unidos a la doctrina Monroe podría forzarlos, a pesar de su renuncia, a ejercer en tales casos un poder policiaco internacional.»

El mesianismo, ya de connotación religiosa como el expuesto por John Fiske y el reverendo Josiah Strog o de clara trascendencia imperialista como el defendido por Beveridge, fue unido durante el período en el que los Estados Unidos alcanzaron su máxima extensión territorial a un racismo que exaltaba las virtudes de la raza germano-sajona. No es pertinente entrar en el análisis de la generación de tales ideas en el ámbito estadounidense, derivadas de las que desde la mitad del siglo XIX tomaron en Europa cada vez mayores pretensiones científicas. Lo importante del tema en señalar la carga racista que las elites influyentes estadounidenses mantenían en el momento del contacto político con Puerto Rico. Si ya Fiske en su Manifiest Destiny había señalado la necesidad de que las dos ramas de la raza sajona extendieran por la mayor parte del mundo los más altos grados de civilización, John W. Burgess explicitaba definitivamente la mentalidad superior: «Teutonic races, Germans and Anglo-Saxons, excelled all other people, past and present»?

${ }^{6}$ Cit. en Mesa Garrido, R., La idea de comunidad iberoamericana: Entre la historia y la utopía. Madrid, CEDEAL, 1989, págs. 25-26.

Pratt, J., op. cit., pág. 4. Un buen análisis de esta base mesiánica y religiosa en Healy, David, U.S. Expansionism. Madison, Wisconsin, 1970, págs. 35 y ss. Compendio de los anteriores, HoRsman, R., La Raza y el Destino Manifiesto. Origenes del anglosajonismo racial norteamericano. México, FCE, 1985. 
Esta superioridad racial y la confesionalidad que los teóricos de la política exterior estadounidense pretendían dar a su desarrollo tienen como consecuencia la creación del mito de «misión», que no es otro que el de elevar la categoria de los habitantes de los nuevos territorios incorporados desde su condición semi-humana hasta las más altas cimas de la civilización. Dicha actitud, que en las postrimerías del siglo XIX podía ser ya aplicada, quedaba justificada por Albert K. Weinberg:

"It comprises metaphysical dogmas of a providential mission and quasiscientific "laws" of national development, conceptions of national right and social duty" ".

Algunos meses antes de la entrada de los marins en La Habana y San Juan, Benjamin Kidd publicaba The Control of the Tropics, donde el concepto de misión se equipara a los intereses económicos y políticos. Kidd mantenía que la extensión colonial estadounidense (ya fuera simple penetración económica o expansión territorial), no sólo era beneficiosa para Estados Unidos, sino que sobre todo resultaba imprescindible para los pueblos a los que se les concedía la oportunidad de ser colonizados, dado que de la presencia o ausencia estadounidense dependía el progreso de la civilización o la permanencia en la anarquía:

"The tropical peoples were as children; they could neither govern themselves or develop their land, and non-colonial tropical societies could be characterized by the words "anarchy and bankruptcy"" ".

Esta era la opinión sobre el papel que Estados Unidos debía ejercer en los territorios que pasaban a su responsabilidad por la firma del tratado de París.

Ya habian sido superados los presupuestos anexionistas que se habian puesto en práctica hasta la guerra de Secesión; la compra de Alaska y las islas Midway en 1867, junto a las Hawaii posteriormente, aun respondiendo a unos intereses más concretos acabaron siendo tratados como los territorios incorporados (en 1959 alcanzaron status de estados). Pero las islas colocadas en 1898 bajo la bandera estadounidense siguiendo las teorías de Mahan fueron los primeros casos en que se puso en práctica el colonialismo teorizado por Fiske, Strog, Burgess o Turner. Era la primera ocasión en que el cambio de soberanía del territorio no conllevaba

${ }^{8}$ Weinberg, A. R., Manifiest Destiny. Glorichester, Mass., Peter Smith, 1958, pág. 2.

${ }^{9}$ Rep. en Healy, D., op. cit., pág. 132. 
ninguna promesa de incorporación a la Unión como un estado más, con disfrute de la ciudadanía para sus habitantes. Esto tenía mucho que ver con las ideas mesiánicas y los prejuicios racistas antes apuntados, más que con la diferencia demográfica con los anteriores territorios.

El hecho fundamental que supuso el paso definitivo hacia la práctica del colonialismo estadounidense fueron los intereses económicos. Como ha estudiado el profesor Lyman J. Gould, el inicio del colonialismo por Estados Unidos no se produjo tanto por buscar una cobertura para la explotación, que podía garantizarse por otros medios incluso en estados independientes, sino por un instinto defensivo cuyo origen se encontraba en la semejanza de las situaciones de las islas caribeñas y Filipinas. $\mathrm{Ni}$ Puerto Rico ni Cuba representaban un peligro en producción de cualquier tipo o en mano de obra para la metrópoli; pero Filipinas era considerada la puerta por donde productos asiáticos e incluso europeos podían inundar Estados Unidos. La imposibilidad de legislar directamente sobre el archipiélago a causa de la guerra allí desatada tras 1898 aconsejaron un tratamiento proteccionista, en el que el Congreso mantenía el usufructo de todos los beneficios del mercado con los nuevos territorios y su control político como entidades "protegidas» ${ }^{10}$.

Este cambio en la política de expansión se produjo en plena reactivación neocolonial y en consecuencia, siguiendo el ejemplo de las potencias europeas, Estados Unidos también quiso poseer su propio imperio " ${ }^{11}$. En ningún caso de los que a partir de entonces se generaron se presentó tan visible el paso del expansionismo al colonialismo como en Puerto Rico. Tanto a Cuba como a Filipinas se les concedió en los años posteriores la posibilidad de constituirse en estados independientes, si bien fuertemente mediatizados por Washington. Puerto Rico no tuvo tan siquiera el privilegio de ser colocado bajo una Enmienda Platt a la constitución cubana o un artículo VII del tratado con Panamá.

${ }^{10}$ Uno de los mejores estudios del paso de Estados Unidos del expansionismo asimilista al colonialismo y su primera aplicación, en Puerto Rico, Gould, L. J., La Ley Foraker: Raices de la politica colonial de los Estados Unidos. [Río Piedras], Editorial de la Universidad de Puerto Rico, 1969. Aunque inédita, es muy interesante la tesis de Gannon, Peter Steven, The ideology of americanization in Puerto Rico, 1898-1909. Conquest and disestablishment. Ph. D. New York University, 1979; Centro de Estudios Avanzados de Puerto Rico y el Caribe (CEA).

No se entra aquí en el debate sobre si la vocación imperial de Estados Unidos deviene del momento mismo de su independencia o nació con motivo del expansionismo continental y su posterior colonialismo; defendiendo ambos puntos de vista y por mencionar sólo bibliografía estadounidense vid. Groover, Rebecca B., American Nationalism 1783-1830. Nueva York, G. P. Putnam's Son, 1970; y VAN Alstyne, R. W., The Rising American Empire. Chicago, Quiadrangle Books, 1965; frente a WITAKER, A. P., The Western hemisphere idea: Its rise and decline. Ithaca, Correll University Press, 1969. 


\section{CAMPAÑA DE ACULTURACIÓN MEDIANTE LA DESHISPANIZACIÓN: PROGRAMAS EDUCATIVOS ESTADOUNIDENSES}

Con los prejuicios antes enunciados llegaron las tropas estadounidenses a Puerto Rico, siendo recibidas de distinto modo según los ambientes y personalidades de grupos políticos de la isla. No cabe duda que por regla general la presencia de los marines fue acogida como una liberación, sin llegar al extremo de cierto personaje que ganado por la emoción cayó de rodillas con ojos llorosos ante las milicias estadounidenses llamándoles "enviados de la libertad". También hubo desplantes e incluso ataques que tuvieron que padecer soldados y mandos por quienes, en busca de la verdadera independencia, desde un principio comprendieron el flaco favor que aquellos pretendian hacer en su defensa ${ }^{12}$.

Junto con las tropas, y aún más impregnados de las ideas y prejuicios ya señalados, llegaron los hombres encargados de asimilar el nuevo territorio al ámbito político, económico y cultural de Estados Unidos. Desde un primer momento el mayor obstáculo encontrado fue la comunicación entre la anterior cúpula dirigente y los nuevos detentadores del poder. Es en este sentido donde se deben encuadrar las subidas fulgurantes de algunos personajes cuyo único bagaje, desde ético a político, era el conocimiento de la lengua inglesa. Para profundizar en la asimilación general de la población se vio rápidamente que no existía más solución que apostar por una trasformación radical en el sistema educativo. Por este medio se trató de llevar a efecto los cambios que ya pidiera el que fuera último cónsul estadounidense en Puerto Rico, Phillip C. Hanna:

"Lo mejor para esta isla es que todo lo español sea totalmente cambiado, la forma de gobierno español, el derecho español, los tribunales españoles,... las costumbres españolas, el sistema educativo español,... y yo espero que también el idioma español sea cosa del pasado en la isla" ${ }^{13}$.

Los hechos inmediatamente posteriores no dejaron ninguna duda de que la opinión del cónsul estaba generalizada en los círculos políticos de Washington; cada uno de los puntos tuvo un seguimiento escrupuloso tras la entrada de las fuerzas de ocupación.

Los dos primeros educadores enviados por Washington para estudiar la implantación adaptada del sistema educativo estadounidense fueron los

12. DE Diego, J., Nuevas campañas: Independencia de Puerto Rico. Unión Antillana. Solidaridad Ibero-Americana. Barcelona, Sociedad General de Publicaciones, 1916, págs. 336 y ss.

13 Rep. en Delgado Citrón, C. op. cit, págs. 3-4 
doctores John Eaton y Victor S. Clark. Su conocimiento sobre el terreno les determinó a llevar a cabo un cambio radical que alcanzaba hábitos y costumbres, enseñanzas y métodos, teniendo en la total sustitución del inglés por el español su punta de lanza más efectiva. Las razones por las que debía llevarse a efecto dicho cambio eran de tipo socio-político: una pertenencia de la población de la siguiente generación al ámbito estadounidense facilitaría una asimilación casi instantánea, al tiempo que haría disponible la incorporación puertorriqueña al escenario económico, laboral $y$, en menor importancia, cultural de Estados Unidos. No se hacían ver las posibles contraindicaciones de la medida, dado que, como aseguraba el doctor Clark, era poco y de nula importancia lo que podría ser destruido y su aprecio por los nativos era muy escaso:

"In conclusion we would say that careful study of the history of the public school of Puerto Rico, as outlined in the secretary's report, will help one much in appreciating the character of the problem here. There does not seem to be among the nasses the same devotion to their native tongue or any national ideal that animates the Frenchman, for instance, in Canada or the Rhine provinces. Another important fact that must not be overlooked, is that a majority of the people of this island does not speak pure spanish. Their language is a patois almost unintelligible to the natives of Barcelona and Madrid. It possesses no literature and has little value as an intelectual medium ${ }^{14}$.

El objetivo del cambio no podía ser otro que el de permitir una fácil asimilación de los habitantes de la isla al sistema estadounidense, independientemente del futuro político que las autoridades de Washington otorgaran a la condición constitucional de Puerto Rico:

"Una educación que busca el cambio del idioma nativo envolverá el cambio de la religión y un cambio en todo el cúmulo de tradiciones del pueblo: ${ }^{15}$.

Es perceptible en este primer acercamiento a la opinión de los comisionados estadounidenses que está presente en su actuación dos cla-

${ }^{14}$ CLARK, V. S., informe al Departamento de Estado, 1899. Rep. en AGUILO SILVA, S., Idea y concepto de la cultura puertorriqueña en la década del 1950. San Juan, CEA, 1987 (inédito), pág. 111.

${ }_{15}$ W. T. Harris, Comisionado de Educación de Estados Unidos, a Victor S. Clark, Presidente de la Junta de Educación durante el gobierno militar; rep. en Garcia MARTínEZ, A. L., "Las fuerzas juridicas en la reconstrucción de la histórica lingüísica de Puerto Rico a partir de 1898 ", en Problemas jurídicos y constitucionales del idioma español en Puerto Rico. San Juan, RCAPR, 1990, pág. 51. 
ses de prejuicios que trastocan totalmente su visión de la realidad puertorriqueña. Por un lado los anteriormente señalados de superioridad étnica, paternalismo humanista y necesidad colonial. Pero lo más interesante es comprobar cómo se asimilaron las anteriores experiencias de incorporación de territorios y fueron proyectadas en el caso caribeño, sin gastar el mínimo tiempo para tratar de conocer y constatar la existencia de lo que Clark negaba. La incorporación de Texas, Nuevo México y California a los estados de la Unión, territorios pobremente poblados y que además sufrieron una fuerte presión para hacer desaparecer la población allí asentada, dejó prendida la idea de una fácil asimilación de cualquier otro territorio de anterior colonización española. Pero las experiencias no quedaban reducidas a los hechos acaecidos medio siglo antes; la incorporación de Hawaii y posteriormente Filipinas, Marianas y Guam, donde se hablaban un conjunto de lenguas y dialectos sin la preeminencia de ninguno (sólo la elite filipina hablaba español, lo que al cambiar de metrópoli condujo a su casi desaparición) facilitó la preeminencia del inglés en corto espacio de tiempo, constituyéndose en la lengua de comunicación común.

Fue en ese momento, los años de la administración militar, cuando se planteó el problema principal de las relaciones entre Puerto Rico y su nueva metrópoli; este problema encontró en la batalla del idioma un «símbolo" por ambas partes, de ataque y de defensa, de dominio y de independencia. En realidad para ambos bandos el idioma era en principio una cuestión secundaria. Para Estados Unidos la imposición de inglés era el camino más rápido para acometer la asimilación de la isla al mundo anglosajón; como potencia expansiva operaba en coherencia con lo que todos los imperios y naciones colonialistas han tratado de realizar, con diferente éxito, a lo largo de la historia ${ }^{16}$. Por otra parte, para los independentistas y autonomistas puertorriqueños la defensa del español era el medio más seguro de preservación de una cultura y un pasado que los hacía esencialmente "diferentes" de la potencia colonial. Las palabras de la entrañable Nilita Vientos Gastón son explícitas sobre esto:

"No hay aspecto de la historia de Puerto Rico que mejor revele el drama que vive, a causa de su condición política, que el problema de la lengua, la lucha contra el llamado bilingüismo -la pretensión de que el puertorriqueño considere también como propia una lengua ajena: el inglés-. Sólo en un pueblo que carece de soberanía se discute el derecho a colocar la lengua propia por sobre cualquier otra" ${ }^{17}$.

16 Tejerina Montaña, B., Nacionalismo y lengua. Madrid, C.I.S., 1992, pág. 13-64.

17 VIEntos Gastón, N., "El Tribunal Supremo de Puerto Rico y el problema de la lengua", 
Esta batalla del idioma se ha desarrollado a lo largo de cinco fases, la última de las cuales se está dando en los últimos años. Cada una de estas fases se encuentra directamente motivada por cambios en el estatuto jurídico de Puerto Rico, bien como su consecuencia o como instrumento para forzarlos. Aunque es necesario señalar que la evolución sufrida en ellos ha sido determinada por la presión social de ciertos sectores autonomistas e independentistas tanto, o en menor medida, que de las necesidades coloniales estadounidenses.

\section{a) La Ley Foraker: Desidentificación nacional y aculturación}

La primera fase se encuentra directamente relacionada con el cambio ideológico y práctico en la política exterior de Estados Unidos, al pasar de un expansionismo caracterizado por la anexión de nuevos territorios a un imperialismo de dominio no anexionista. Está directamente motivada por la entrada en vigor del primer estatuto político bajo soberanía estadounidense, la carta otorgada conocida por Ley Foraker (1900). Se caracteriza por la paulatina implantación del idioma inglés en todo el sistema educativo; comienza en 1900, cuando el comisionado de educación Martin G. Brumbaugh determinó que el inglés fuera el idioma único para toda la enseñanza no elemental; el español quedaba reducido a la enseñanza primaria, no con afán de preservarlo sino por imposibilidad de encontrar suficientes maestros para llevar a cabo la enseñanza en inglés ${ }^{18}$. Unos años después, su sucesor Samuel McCune Lindsay creyó llegado el momento de ampliar el tramo en el que el inglés fuera enseñado. De ello se encargó el nuevo comisionado Roland P. Falkner, decretando en 1905 la obligatoriedad de tener el inglés como lengua básica en todos los niveles de la enseñanza, relegando el estudio del español a simple asignatura. La paulatina aplicación de dicha legislación, ante el inconveniente de la escasez de maestros con dominio suficiente del inglés y el poco entusiasmo por enriquecerlo, llegó a anunciar la retirada de las licencias de

Casa de las Américas XII, enero-febrero de 1972, núm. 70, pág. 64. Una de las obras que más detenidamente analiza el papel del idioma en la evolución política puertorriqueña es la de GARcía Martínez, A., Idioma y política: El papel desempeñado por los idiomas español e inglés en la relación politica Puerto Rico-Estados Unidos. San Juan, Ed. Cordillera, 1976. Su postura es claramente contraria a la política de "americanización", como ponen de manifiesto estas pala. bras: “El verbo, la palabra es lo primero y la palabra hablada, vibrante, la que sacude y despierta. Después viene todo lo demás" (pág. 141).

18 Cebollero, P. A. La política lingüistico-escolar de Puerto Rico. San Juan, Baldrich, 1945. 2. ${ }^{\mathrm{a}}$ ed., cap. 1. 
todos aquellos educadores que no llevaran a cabo puntualmente las directrices educativas.

Las autoridades contaban con que las escuelas públicas, con su innovadora enseñanza en inglés, fueran "the open door to the federal union", en palabras del comisionado de instrucción Martin Brumbaugh. En consecuencia, en la circular del 19 de enero de 1899 el gobernador militar Guy $V$. Henry decretó que todos los maestros debian dominar el inglés, sin el cual serían apartados del servicio; en adelante los exámenes de Escuela Superior, institutos medios y escuelas públicas serian en inglés. Medidas que en 1903 fueron completadas con la extensión del inglés como único vehículo educativo a todos los niveles ${ }^{19}$. Fue el primer error, quizá el mayor de las autoridades militares; si la escuela pública debía ser esa puerta abierta a la estadidad, los maestros eran necesariamente los instrumentos operativos de esa política, pero el resultado de la normativa del inglés por vía de apremio fue el enfrentamiento desde un principio del decisivo sector de la enseñanza ante el nuevo sistema educativo. Con ello el instrumento más adecuado para la americanización se volvió en el enemigo principal de ella; no fue extraño que la Asociación de Maestros de Puerto Rico, creada en Ponce en 1905, fuera el núcleo más resistente a la política emanada por Washington ${ }^{20}$. Antes de esto, las juntas municipales de instrucción fueron el primer núcleo opositor, negándose a crear un solo centro público al nuevo estilo bajo el gobierno militar. Para paliar esta "negligencia", la creación del Negociado de Instrucción en 1900 absorbió las competencias de las juntas municipales, centralizando el gobierno civil el sistema de enseñanza, algo que no se hacia en los mismos Estados Unidos.

De esta etapa, paralela al cambio en el sistema pedagógico, proviene la transformación del sistema judicial puertorriqueño y la conocida como Ley de los Idiomas Oficiales (1902). Por esta ley se declaran oficiales los idiomas inglés y español, en todos los niveles y en todas las instancias de gobierno, salvo en aquellos casos donde se produzca una intervención

${ }^{19}$ FigueroA, L., op. cit., págs. 39-40. Sobre la elaboración de esta política educativa vid. BEIRNE, C. J., El problema de la "americanización» en las escuelas católicas de Puerto Rico. [Río Piedras], Ed. Universitaria, 1976.

${ }^{20} \mathrm{El}$ año en que se creó la Asociación de Maestros es dudoso. Aunque toda la bibliografia que lo trata determina los años 1911 y 1912 , se ha encontrado documentación que demuestra que existió la Asociación de Maestros de San Juan desde 1902 y la Asociación de Maestros de Puerto Rico se creó en 1905, desconociéndose el por qué los autores puertorriqueños retrasan su constitución más de un lustro; Archivo General de Puerto Rico - Instituto de Cultura Puertorriqueña (AGPR-ICP); fondo: Departamento de Estado; serie: Corporaciones sin fines de lucro; Caja 2, exps. 28 y 29. 
federal, donde el único idioma oficial sería el inglés. Este bilingüismo oficial teórico tuvo su trasposición a la esfera del derecho mediante la absusción de un sistema jurídico extraño a la historia y el uso de Puerto Rico. A partir de la designación de jueces estadounidenses en suelo puertorriqueño en 1901, y con especial empeño por parte del Tribunal Supremo de Puerto Rico, se introdujo el sistema judicial anglo-americano en detrimento de los ordenamientos jurídicos de tradición civilista; la Common Law se barajó con el Derecho Civil. El resultado del uso paralelo de ambos sistemas judiciales, en palabras del anterior Juez Presidente del Tribunal Supremo, don José Trías Monge, ha sido que "a Puerto Rico le toca la amarga distinción de contarse entre los primeros países que crearon el Derecho Absurdo" ${ }^{21}$.

En esta época se pusieron en marcha los principales mecanismos de asimilación mediante la trasculturación. El uso exclusivo del inglés se complementaba con toda una serie de incorporaciones estadounidenses y de omisiones de la historia y la tradición puertorriqueña. Como señalaba con un punto de ironía Ricardo Alegría:

"La historia de Puerto Rico y la vida de nuestros hombres ilustres era ignorada en nuestras escuelas, donde eran temas obligados de estudio la historia de los Estados Unidos y la vida de las grandes figuras norteamericanas, y donde nuestros estudiantes debian celebrar con actos apropiados las fiestas tradicionales de los Estados Unidos. Aun la celebración de la Navidad era celebrada como "White Christmas", a pesar de que nuestros niños nunca habian visto la nieve" ${ }^{22}$.

\section{b) Ley Jones: Ciudadanía estadounidense y bilingüismo}

Más que las presiones llevadas a cabo por los autonomistas contra las medidas impositivas, fue la constatación del fracaso del sistema lo que hizo replantearse la situación a las autoridades estadounidenses, que dictaron a la isla una segunda carta otorgada - la conocida por Ley Jones (1917) - , que llevaba anexa la concesión de la ciudadanía estadounidense. Idiomáticamente, un nuevo proyecto presentado por el comisionado

21 Trias Monge, J., "La crisis del Derecho en Puerto Rico", Revista Juridica de la Universidad de Puerto Rico. San Juan 1980, vol. LXIX.

${ }_{22}$ Alegría, R. E., Status of Puerto Rico. Hearins before the United States - Puerto Rico Commission on the Status of Puerto Rico. Washington, Government Printing Office, 1966, 3 vols., vol. II: Socio-Cultural Factors in the Relation to the Status of Puerto Rico, págs. 17-18. 
de instrucción Paul G. Miller en 1916 consistía en hacer copartícipes al inglés y el español; era en realidad el primer punto de retorno en la política educativa del gobierno estadounidense en la isla. El español sería el lenguaje de la enseñanza hasta quinto grado, donde entraba en contacto con la lengua inglesa, en la que se impartían el resto de la enseñanza media y superior; dicha estructura pedagógica estuvo en vigor, salvo muy pequeños retoques, hasta 1934. Durante esta segunda etapa las protestas contra el sistema encontraron foros más amplios y se organizaron campañas más meditadas, al tiempo que la cuestión del idioma toma su mayoría de edad política ${ }^{23}$.

\section{c) Desamericanización oficial, hispanización educativa}

El final de la etapa anterior estuvo señalado por el nombramiento del primer puertorriqueño en el cargo de Comisionado de Instrucción, el doctor José Padín, quien tomó posesión de su cargo en 1930; durante los primeros cuatro años de su gestión prolongó el sistema anterior. Pero a partir de 1934 dio paso a una nueva etapa, con un mayor criterio pedagógico: la enseñanza primaria se impartiría totalmente en español, creándose una asignatura en inglés que se encargaba a los maestros más adecuados para ella. Con la base lingüística obtenida en los ocho años primarios, el bachiller se consideraba que podía ser impartido en inglés. A pesar de lo modesto de la aportación fue la primera ocasión en que explícitamente se trató de desvincular la cuestión pedagógica (no la del idioma) de las luchas de los partidos políticos, que para esa década debatían acaloradamente el tema.

Esto se manifestó en las duras críticas que a la política de Padín hicieron tanto la asocación de maestros como los sectores estadistas. La presión de éstos acerca de Washington fue presentada como una campaña en defensa del inglés ante aquellos que se oponían a toda referencia a ese idioma en Puerto Rico. Ésta fue pues la característica de la época: presión por ambos bandos y mantenimiento del sistema presentado. Se mantuvo incluso cuando las sugerencias de Washington perdieron toda su sutileza y el mismo Presidente Roosevelt en carta al nuevo comisionado, doctor José $M$. Gallardo, insistía en la necesidad de que se intensificara en Puerto Rico la enseñanza del inglés, entendiéndose que la enseñanza debía ser impartida en dicha lengua:

\footnotetext{
${ }^{23}$ Negrón de Montilla, A., Americanization in Puerto Rico and the public school system in Puerto Rico, 1900-1930. San Juan, Edil, 1970.
} 
"Quiero expresarle con toda claridad el punto de vista de mi administración con respecto al muy importante asunto de la enseñanza del inglés en esa isla... Parte indispensable de la politica americana, consiste en que la próxima generación de ciudadanos americanos de Puerto Rico crezca con un completo dominio de la lengua inglesa. El inglés es el idioma de nuestra nación” ${ }^{24}$.

\section{d) Hacia la identificación nacional mediante el idioma}

Los años cuarenta suponen la cuarta etapa de la contienda lingüística y es en gran medida el colofón de la evolución de la precedente; se caracteriza por una paulatina pérdida de preeminencia del inglés y una apuesta decidida por la enseñanza en castellano. La primera medida importante en este sentido fue la resolución del Consejo Superior de Enseñanza, a los pocos meses de ser creado, en la que se disponía que el idioma español fuera preferente en las aulas de la Universidad de Puerto Rico (15 de junio de 1942). En 1946 fue designado como Comisionado de Instrucción Mariano Villaronga, quien incluso antes de tomar posesión del cargo anunció que era su intención hacer del español el vehículo de enseñanza a todos los niveles; declaración que bastó para que la ratificación de su nombramiento fuera demorada por el Senado Federal y el candidato decidiera renunciar al puesto. Éste quedó vacante, pero el comisionado interino, Francisco Collazo llevó adelante una prueba piloto en varias escuelas intermedias en el curso 1947-1948. El resultado de la prueba fue que el español era el vehículo pedagógico más adecuado para la enseñanza en todas las escuelas intermedias; y así fue decretado, con lo que el inglés quedaba como lengua principal sólo en los tres años de enseñanza secundaria.

Uniéndose una vez más idioma y política, el paso definitivo se dio en 1848, cuando el pueblo de Puerto Rico pudo por primera vez elegir directamente a su Gobernador. El Gobernador electo, Luis Muñoz Marín, nombró a Mariano Villaronga para el cargo antes propuesto; en virtud de las enmiendas aprobadas por el Congreso Federal a la Ley Orgánica, los nombramientos del Gobernador no debían pasar otro trámite y en con-

24 Rep. en Ferrer Canales, J., For nuestra lengua y nuestra soberanía. mensaje leído ante el III Congreso del Colegio de Maestros de Cuba, La Habana 6-12 de agosto de 1947. Rep. en Delgado Citrón, C., op. cit., pág. 30. Munoz Souffront, L., El problema del idioma en Puerto Rico. (Esfuerzos de la Asociación de Maestros para alcanzar la solución al problema). San Juan, Biblioteca de Autores de Puerto Rico, 1950, pág. 21. 
secuencia el veto anterior quedaba sin efecto. Una de las primeras medidas de Villaronga fue llevar a efecto su anunciada medida: decretó que todo el sistema educativo público en Puerto Rico tomara el español como lengua a partir el curso 1949-1950. Existiendo la igualdad jurídica de ambos idiomas, la preeminencia oficial correspondía al español. Símbolo de nuevo de un cambio sustancial en el régimen político puertorriqueño: dos años después Muñoz Marín conseguía la aprobación por sus conciudadanos y por Washington de la constitución de Puerto Rico como Estado Libre Asociado.

La última fase de la "batalla del idioma", que más adelante se estudia, se está produciendo en los últimos años.

\section{LA RESPUESTA ANTE LOS INTENTOS DE ASIMILACIÓN Y DESIDENTIFICACIÓN NACIONAL: LOS PARTIDOS POLITICOS PUERTORRIQUEÑOS}

Acaba Lyman J. Gould su magnífico estudio sobre la Ley Foraker hablando sobre la «ironía histórica» que ha sufrido el tratamiento dado por Washington a Puerto Rico. Mientras que a Filipinas, origen decisivo para la transformación del expansionismo anexionista al colonialismo, se le acabó liberando de toda sujeción colonial y a los ejemplos análogos al caso puertorriqueño como Hawaii y Alaska se les otorgó la estadidad, Puerto Rico permanece como territorio no incorporado mediante el estatuto de Estado Libre Asociado: "Tal vez los republicanos legislaron, como ellos alegaron en 1900, teniendo en mente sólo el bienestar de los puertorriqueños» ${ }^{25}$.

Las bondades altruistas de los congresistas republicanos no se escaparon ni siquiera a los hombres que, habiendo combatido por el fin de la presencia española en la isla, vieron en la presencia estadounidense la oportunidad de elevar a Puerto Rico al nivel de las modernas naciones libres. Pero pronto cundió el desencanto, puesto que los mismos «no podían entender que bajo una monarquía que se tildaba de caduca y tiránica se hubiera podido tener un gobierno autónomo y que bajo la "Gran República" tuviesen que ser gobernados militarmente" ${ }^{26}$. Como tampoco podía recibirse con agrado que la primera medida de las auto-

25 Gould, L. J., op. cit., pág. 174.

${ }^{26}$ Figueroa, L., Tres puntos claves: Lares-idioma-soberania. San Juan, Ed. Edil, 1972, pág. 43 
ridades militares fuera cambiar el nombre del territorio cedido por el tratado hispano-estadounidense, que se hizo efectivo a partir del 18 de octubre de 1898. La primera edición de la publicación oficial de las autoridades gubernativas, La Gaceta, señala el nuevo territorio bajo su jurisdicción -y por tanto sanciona la denominación-con el nombre de "Porto Rico". De igual modo, fue la primera ocasión en que se utilizó el inglés como vehículo legislativo ${ }^{27}$.

Una segunda medida fue la obligatoriedad de todos aquellos que quisieran conservar la nacionalidad española de ratificar su condición por vía judicial. De no hacerse así antes del 10 de abril de 1900, automáticamente se consideraría que se renunciaba a dicha nacionalidad ${ }^{28}$. La disposición no determina la nacionalidad en que permanecerian todos aquellos que decidiesen permanecer unánimes; al no disponer de la declaración de ciudadanía estadounidense se consideraba que se aceptaba, de facto, la nacionalidad puertorriqueña.

Desde los primeros momentos de la dominación estadounidense surgió el movimiento de oposición al gobierno de una nueva potencia extranjera. El fin de esta oposición era la preservación de la identidad puertorriqueña ante los programas de trasculturación de las autoridades militares y civiles a partir de 1900. Esta defensa de la identidad como pueblo, y por tanto con esperanzas de alcanzar la independencia política, se llevó a cabo en tres niveles. El primero, anteriormente analizado, fue la oposición a la legislación educativa que dictaba la utilización del inglés como único idioma en las aulas. El segundo nivel, íntimamente ligado al anterior, que ha sido su símbolo hasta el presente, lo configura la oposición a la pretensión estadounidense de mantener Puerto Rico como un territorio no incorporado; no se toma partido por ninguna de las partes: independentistas, libreestadistas o estadistas ${ }^{29}$. Lo que ninguno de los grupos políticos nunca quiso fue la permanencia en el estado atípico del reconocimiento de

27 La Gaceta. San Juan 26 de octubre de 1889. Una enumeración exhaustiva de todas las medidas tendentes a transculturizar Puerto Rico en MENDEZ, J. L., La agresión cultural norteamericana en Puerto Rico. México, Grijalvo, 1980.

${ }_{28}$ Esta medida y el archivo abierto por el Brigadier General Davis el 31 de agosto de 1899 para aquellos que mantuvieron la nacionalidad española son un vehículo privilegiado (y hasta la fecha no utilizado) para el estudio de la emigración y la presencia española en la isla a finales del siglo $x \mid x$. Ordenado por cabezas de famiiia, el archivo contiene nombre, edad, "nacionalidad» (provincia o región), estado civil, ocupación y nombre de la esposa e hijos. AGPR-ICP Departamento de Estado; Declaraciones de nacionalidad, tarea 74-†2.

29 Respectivamente los promotores de la soberanía política independiente de Puerto Rico; los sostenedores del actual sistema estatutario, el Estado Libre Asociado; y los propiciadores de la "estadidad" o vinculación total a Estados Unidos como el 51 Estado de la Unión. 
una ciudadanía puertorriqueña y al mismo tiempo la concesión de la estadounidense, sin una vinculación basada en ninguna norma jurídica que partiera del reconocimiento de Puerto Rico como una entidad ${ }^{30}$. El tercer nivel se manifiesta en una dimensión que vincula los anteriores, ampliando su radio de acción; es la defensa de la pertenencia de Puerto Rico al ámbito cultural hispanoamericano y al mundo político latinoamericano.

La batalla del idioma estuvo siempre unida a la contienda por el status político de la isla. El vacío constitucional en el que estaba Puerto Rico desde la cesión de España fue paliado con la aprobación por el Congreso Federal de la "Ley Foraker", que determinaba los poderes ejecutivo, legislativo y judicial, concedía la ciudadanía puertorriqueña y creaba el Negociado de Instrucción. Por esta ley el Presidente de Estados Unidos nombraba a un Gobernador y a su gobierno, el Consejo Ejecutivo, formado por seis estadounidenses (los directores de los consejos administrativos) y cinco puertorriqueños; se creaban dos cámaras legislativas: el Senado, también de nominación presidencial, y la Asamblea Legislativa, cámara alta compuesta por treinta y cinco miembros elegidos por sufragio directo cada dos años. La administración de justicia fue depositada en las cortes municipales, las cortes de distrito, un tribunal supremo y una corte federal de los Estados Unidos ${ }^{31}$.

Aunque muy reducida, a partir de ese momento la participación de los partidos políticos puertorriqueños comenzó a generalizarse, en gran parte como respuesta contraria al espíritu colonial de la Ley Foraker. Es también a partir de esa época cuando los partidos toman una característica que los hace especialmente peculiares en todo el ámbito americano: la definición en cuanto al posicionamiento respecto al status que debe alcanzar Puerto Rico, siendo secundario todo otro planteamiento idelógico.

En este sentido y de acuerdo con la situación de principios de siglo existían tres posibilidades en el panorama político puertorriqueño: el apoyo a las medidas impuestas por Estados Unidos, la presión para la integración de la isla en la Unión y la lucha por superar el planteamiento colonial e iniciar el camino hacia la independencia. Las dos primeras opciones fueron asumidas por el "Partido Republicano Puertorriqueño», filial del homónimo continental y heredero directo de la sección puertorriqueña

${ }^{30} \mathrm{Vid}$. desde posturas antagónicas las aportaciones al debate de COLL CUCHI, J., El nacionalismo en Puerto Rico. San Juan, s.e., 1923; у Aмr. F. J., Predicar en el desierto. San Juan, Tip. «El Alba», 1907.

${ }^{31}$ Ludue dE SANCHEz, M. ${ }^{a}$ D., La ocupación norteamericana y la Ley Foraker (La opinión pública puertorriqueña). Río Piedras, Ed. Universitaria, 1980. 
del Partido Republicano español. La tercera vía, si bien tímidamente al principio, acabó siendo defendida por el antiguo Partido Autonomista ${ }^{32}$, reformado y reestructurado por Luis Muñoz Rivera, que pasó a denominarse primero Liberal, luego Federal y por último «Partido Unión» de Puerto Rico ${ }^{33}$. En las elecciones de 1900 el Partido Federal reusó presentarse por considerar que la Ley Forker

"es una red dentro de la cual se nos encierra sin misericordia, privándonos de todo derecho y obligándonos a pensar que se quiere reducirnos a la triste condición de siervos romanos, adscritos al terruño, impotentes para cualquier iniciativa y condenados a una inferioridad injuriosa, frente a la cual se alza siempre la protesta de los hombres libres" ${ }^{34}$.

La consecuencia fue la ocupación total de la cámara por el Partido Republicano, cuya única crítica a los gobernantes estadounidenses era que no se hiciera más rápida y profunda la integración de Puerto Rico.

Paradójicamente ambos partidos vieron satisfechos sus deseos. El Partido Federal fue reestructurado en 1904, fundándose el Partido Unionista, que a partir de las elecciones de ese mismo año detentará en la Cámara Legislativa la mayoría absoluta; su líder Muñoz Rivera aceptó en 1910 el puesto de Comisionado Residente, representante de Puerto Rico en todos los cuerpos administrativos federales en Washington, de modo significativo ante el Congreso. Su labor, junto a los acontecimientos que se sucedian en la isla que evidenciaban las carencias de la Ley Foraker, consiguieron de la Cámara su sustitución por una nueva Carta Orgánica, la "Ley Jones". Curiosamente, la gran aportación de esta nueva carta es la concesión de la ciudadanía estadounidense a todos los puertorriqueños, petición que había hecho con especial insistencia el Partido Republicano. Los otros cambios significativos fueron la eliminación del Consejo Ejecutivo y la elección total del Senado, encargado de ratificar los nombramientos del Gobernador. Pero existían dos excepciones, no menos sig-

\footnotetext{
32 Sobre el seguimiento que dicha sección hacía de las directrices emanadas de la Península es interesante el libro de CEPEDA. Francisco, Conferencia de Abuli, celebradas con el Jefe de la minoria Autonomista Parlamentaria, don Rafael Maria de Labra, sobre política antillana, sus relaciones con la politica peninsular y procedimientos que deben seguirse en interés de la reforma colonial. Ponce, Tip. de la Revista de Puerto Rico, 1890.

${ }_{33}$ Un buen estudio a través de su órgano oficioso, La Democracia (fundado por Muñoz Rivera en 1890), en NEGRón PORTILLO, M., El autonomismo puertorriqueño, su transformación ideológica (1895-1914). Río Piedras, Ed. Huracán, 1981. Sobre la creación y evolución de los partidos políticos puertorriqueños, vid. el estudio clásico de Bolivar PAGÁN, Historia de los partidos políticos puertorriqueños, 1898-1965. Barcelona, Tip. Ponceja, 1972, 2 vols.

${ }_{34}$ Carta de Muñoz Rivera al Presidente McKinley; rep. en BENITEZ, J., La desconolonización de Puerto Rico, texio original de la conferencia en el «Foro de Iberoamérica». Universidad de Salamanca, 20-24 de mayo de 1991 (inédito).
} 
nificativas, a esta norma: el Procurador General y el Secretario de Instrucción pública, con lo que se seguía controlando directamente desde Washington los dos campos más importantes de americanización: la enseñanza y el sistema judicial.

A pesar de sus numerosos apologetas, no puede mantenerse seriamente que el cambio entre las Leyes Foraker y Jones lo consiguiera la gestión de Muñoz Rivera en Washington, sin por ello querer quitar importancia a la decisiva labor del líder autonomista. Fue la reacción ante la política de asimilación que pusieron en práctica las autoridades estadounidenses y muy especialmente la prepotencia de la que hacía gala alguna de ellas ${ }^{35}$, lo que llevó a la creación de movimientos de resistencia ante esa política.

Como posteriormente se analizará, uno de los más trascendentales fue la generación de un movimiento cultural de clara vocación reivindicativa, tanto del idioma español, la tradición cultural del siglo xIX y la identidad puertorriqueña. A esta vuelta a las raíces en el campo cultural corresponde en los años veinte y treinta una paulatina radicalización de las posturas políticas. Lo acomodaticio del Partido Republicano ante el gobierno coIonial estadounidense le hizo perder simpatizantes y apoyos tras ser conseguida ademas una de sus bases programáticas: la concesión de la ciudadanía estadounidense. En esta tesitura el Partido Unionista se encontraba en disposición de comandar el panorama político, pero las autoridades estadounidenses extremaron los rigores contra sus manifestaciones más atentatorias para la permanencia del status. En 1921 el gobernador Mont Reilly (conocido coloquialmente por Moncho Reyes) comenzó una campaña de persecución sobre las máximas personalidades contrarias a la administración estadounidense. Esto podía conllevar una prohibición o desaparición del Partido Unionista, por lo que parte de sus dirigentes (en abierta lucha tras la desaparición de Muñoz Rivera) iniciaron una política que llevó a planteamientos más moderados: borraron de su programa la reclamación de independencia política y se reiteró el acatamiento de Puerto Rico a las leyes federales y la lealtad a los Estados Unidos.

${ }^{35}$ Existe un extenso repertorio de hechos, algunos meras anécdotas, que con un alto contenido simbólico han sido aprovechados de un modo efectista en un buen número de obras opuestas a la presencia estadounidense es Puerto Rico o a su influencia cultural; vid. COLL Cuchi, J., Un problema en América. México, Jus, 1944. Beauchap, J. J. (et alii), La agresión cultural norteamericana en Puerto Rico. México, Grijalvo, 1980. Barrios Martinez, R., La independencia de Puerto Rico. Razón y lucha. México, Línea, 1983. 
La ruptura no tardó en producirse. El ala independentista del Partido Unionista decidió romper su militancia y regresar a los planteamientos anteriores. El 17 de septiembre de 1922 se fundó el Partido Nacionalista, con José Coll Cuchí como presidente y Albizu Campos como dirigente más destacado. Durante la década de los veinte el partido consiguió una progresiva implantación, abundando los debates internos sobre la orientación ideológica, independientemente de su posición ante el rango constitucional de la is $\mid \mathrm{a}^{36}$. Las protestas fueron en aumento durante los treinta al tiempo que las autoridades gubernativas aplicaban la política más burda del palo y la zanahoria: la elección del Presidente Roosevelt conllevó la extensión de los programas de ayuda federal a Puerto Rico, al tiempo que se desataba una campaña de represión hacia las actividades y los líderes del Partido Nacionalista.

El proyecto legislativo de tomar la bandera puertorriqueña como símbolo oficial (habiendo estado perseguida hasta años antes), desató la oposición de los nacionalistas que irrumpieron en el Capitolio, produciéndose un muerto (1932). A partir del 24 de octubre de 1935 comienza el punto álgido de la represión; ese día fueron asesinados por la policía cuatro militantes del Partido Nacionalista en el pueblo de Río Piedras; unos meses después dos correligionarios asesinaron al coronel que dirigió esa fuerza de policía; tras ser capturados los dos nacionalistas fueron ejecutados en la misma cárcel. Previendo el crecimiento de desórdenes, la Corte Federal dictó el encarcelamiento de la cúpula del Partido Nacionalista por "conspirar para derrocar a los Estados Unidos por la fuerza». El encarcelamiento de Albizu Campos y otros líderes promovió campañas de protesta; en una manifestación de Ponce la policía disparó contra los congregados produciendo diecinueve muertos. La situación política había llegado a un extremo de difícil solución: un país dividido, al borde de una guerra civil y de independencia, con la cúpula independentista en la cárcel y los puertorriqueños estadistas sometidos a los dictados de las autoridades coloniales ${ }^{37}$.

La historiografía puertorriqueña está dramáticamente dividida en la apreciación de los anteriores acontecimientos y los que, menos dramá-

${ }^{36}$ Torres Ortiz, J. B., Historia del Partido Nacionalista de Puerto Rico, 1922-1937. San Juan, CEA, 1974 (inédito). Alsina Orozco, A., Los Congresos Pro-Independencia. San Juan, CEA, 1987 (inédito)

${ }^{37}$ Pagan, B., op. cit. Géigel Polanco, V., La independencia de Puerto Rico: Sus bases históricas, económicas y culturales. Río Piedras, Ed. Fraternidad Alpha Beta Chi, 1943. MALdonado DeNIS, M., Puerto Rico. Una integración histórico-social. México, Siglo XXI Ed., 8. a ed. [1978]. Una biografía sobre una de las personalidades más influyentes en este proceso: CORRETJER, $J$. A., Albizu Campos. Montevideo, El Siglo llustrado, 1970. 
ticamente, siguieron. La figura indiscutiblemente más trascendental de esa coyuntura fue Luis Muñoz Marín, hijo de Muñoz Rivera. En 1931 había regresado de un autoexilio en Estados Unidos; siendo uno de los hombres que mejor conocía la política interior de su pais y estaba conectado con las esferas de poder de Washington, ignoró la participación en el partido que su padre había creado. Los acontecimientos anteriores le empujaron a fundar en 1938 el Partido Popular Democrático (PPD), que rápidamente supo ganarse las simpatías de los nacionalistas y gran parte del antiguo Partido Unionista. El crecimiento fue tan rápido que en 1940 los populares ganaron las elecciones legislativas, 10 que se repitió más contundentemente en 1944. Durante toda la década y especialmente después del segundo triunfo la evolución política de Muñoz Marín condujo a un apartamiento de la cúpula dirigente del partido de los sectores independentistas, anulando su influencia; desprendido de esta rémora que hacía aparecer al PPD como peligroso ante las autoridades estadounidenses, Muñoz Marín fue pidiendo cada vez con más fuerza mayores parcelas de autonomía ${ }^{38}$. Lo verdaderamente importante de este período desde las esferas populistas fue la sustitución de la independencia por la autonomía y cómo la corriente independentista fue utilizada para alcanzar esas cotas de autogobierno.

El último gobernador estadounidense Rex Guy Tugwell vetó en 1945 un proyecto legislativo que aseguraba que todas las materias educativas fueran impartidas en español; un año después el veto fue ratificado por el Presidente Truman. En esa coyuntura los populares tomaron la bandera del idioma y con ayuda de los sectores independentistas desencadenaron unas campañas de protestas sin precedentes, en la que todas las asociaciones cívicas, educativas (docentes y estudiantes) y de otros campos de la vida pública puertorriqueña fueron movilizadas. El campo estaba abonado; sólo era necesario que se supiera encauzar esa corriente autonómica; en lugar de las armas como en la década anterior, hablaron las urnas y Muñoz Marín fue el primer gobernador electo.

Una vez Muñoz Marín en La Fortaleza, puso en práctica los programas educativos que se habían solicitado en la movilización previa, al tiempo que se reforzaba la campaña contra los independentistas ante la opinión pública mediante la conocida como "ley de la mordaza». Desestigmatizado el movimiento autonomista ante Washington, el Congreso estadounidense aprobó con escasa dificultad la convocatoria de un referéndum para dar

${ }^{38}$ FarR, K., Personalismo y politica de partidos: La institucionalización del Partido Popular Democrático. Hato Rey, Inter American University Press, 1975. 
a Puerto Rico un nuevo orden constitucional; el referéndum de 1951, boicoteado por los independentistas, fue ganado por la tesis presentada por el PPD. El Estado Libre Asociado (ELA) fue proclamado el 25 de julio de $1952^{39}$. Esa fecha había sido festejada anualmente por los estadistas, celebrando el día de desembarco de las fuerzas estadounidenses en 1898; a partir de entonces, y con una premeditación evidente, cambió su significado radicalmente.

\section{LA RESPUESTA A LOS INTENTOS DE TRANSCULTURACIÓN Y AMERICANIZACIÓN: LA PROYECCIÓN CULTURAL PUERTORRIQUEÑA}

Complementaria a la labor de los partidos políticos, y en muchos casos siendo utilizada cuando las presiones coloniales estadounidenses era especialmente sentidas, se desarrolló una tarea de concienciación nacional mediante el fortalecimiento de una cultura propiamente puertorriqueña, desarrollada en español y con una vocación reivindicativa explícita.

Uno de los más activos núcleos generadores de esta promoción cultural fue el Ateneo de San Juan, especialmente a partir de la publicación de su Revista del Ateneo, cuyo objeto era "compendiar y difundir la cultura puertorriqueña en todos los órdenes». El artículo que sirvió como presentación y programa de la revista fue en sí una llamada para la defensa de la cultura puertorriqueña, en medio de un pesimismo y desilusión que el autor no hace esfuerzo en ocultar. Fue al mismo tiempo una queja desde los sectores intelectuales ante el desprecio que las autoridades habían mantenido hacia la herencia cultural del siglo xIx y la creación cohetánea; por ello la llamada fue dirigida hacia «los espíritus cultos», con el fin de llevar a cabo «una obra de intenso poder intelectual». Implícitamente se requiere la concurrencia en la línea de la alta cultura tradicional, lo que a principios de siglo significaba la revitalización de la herencia cultural española. Esta reafirmación de la personalidad nacional mediante una cultura que por sí es fundamentalmente distinta de la anglosajona es el inicio - como lo fue el idioma- de la utilización de esa herencia cultural como elemento conformador de un pueblo:

"La vida intelectual de Puerto Rico debe reflejarse de modo que brille y persista en la continuidad del tiempo, [...]. [La revista] queremos que

\footnotetext{
${ }^{39}$ Sobre el procedimiento de creación y las bases jurídicas y del derecho internacional en las que se asentaba, así como un recorrido histórico posterior, vid. FERNOS ISERN, A., Estado Libre Asociado de Puerto Rico. Antecedentes, creación y desarrollo hasta la época presente. Rio Piedras, Ed. Universitaria, 1974.
} 
lleve la savia pura de nuestra personalidad, que afirme el amor en la familia y en la patria; que pregone nuestra cultura y sea su barómetro fiel $\times{ }^{40}$.

No menos importancia tuvo el giro que dio la publicación del oficioso órgano del Partido Unionista, La Democracia. Pasó de apoyar la labor de americanización de las autoridades a la defensa de las costumbres, religión, cultura e idioma tradicionales en la isla. En esta larga campaña se presentan las mismas características que en la publicación del Ateneo: pesimismo, fatalidad, desazón. El panorama político puertorriqueño era contemplado como una lucha fratricida entre los acólitos de Washington y los defensores de la peculiaridad puertorriqueña; el pesimismo les hacía ver como inevitable a más corto o largo plazo la asimilación y la absorción, y con ellas la desaparición de Puerto Rico en cuanto entidad. Para hacer imposible lo que a veces se califica de fatal, sólo se cuenta con la personalidad cultural tradicional. Por ello de nuevo se utiliza la pervivencia del legado hispano (mediante la defensa de instituciones y costumbres antes criticadas y tildadas de conservadoras, como la Iglesia católica, y las prácticas religiosas que el pueblo había sincretizado) como instrumento de oposición a la política asimilista estadounidense.

A esta campaña no permanecieron ajenos quienes con no menor temor veían la agresiva administración federal: los españoles residentes en la isla, aquellos que explícitamente habian debido mantener su condición de ciudadanos españoles renunciando a la puertorriqueña y a la protección estadounidense. Al despuntar el siglo comienzan a constituirse asociaciones de todo tipo, sobre todo recreativas, que enarbolan una bandera sobre la que aún pesaba la sombra de la derrota. En prácticamente todas las grandes ciudades se encuentra un "Casino Español» o "Centro Español», además de las organizadas "Colonias Españolas"; especialmente importantes en el campo de la beneficencia han sido la Unión Española de Auxilios Mutuos de Mayagües y la Sociedad Española de Auxilio Mutuo y Beneficencia de San Juan de Puerto Rico ${ }^{41}$. Mención aparte merece la

${ }^{40}$ Como las anteriores citas, Quevedo Báez, M., “Intenciones y fines de la revista», Revista del Ateneo, junio de 1905, núm. 1, pág. 1.

${ }^{41}$ Está por hacer el estudio del asociacionismo español en Puerto Rico, lo que se complica en comparación con otros países americanos al no mantenerse en la actualidad la mayoria de estas instituciones. La mayor parte de la documentación consultada se encuentra en AGPRICP: Departamento de Estado; Instituciones sin fines de lucro; cajas núms. 2, 4, 5, 6, 9, 10, 19 y 3-A. Lo más importante aparecido, aunque no supera la mera enumeración, es la obra de Blanco Fernández, A., Instituciones principales españolas y puertorriqueñas de Auxilio Mutuo, Beneficencia, Civicas, Sociales, Culturales y de Fomento. En España y Puerto Rico, 1820-1930. San Juan, Tip. Cantero, Fernández y Co., 1930. Más riguroso, aunque circunscrito al hecho inmigratorio y los casos particulares, es la obra de CIFRE DE LOUBRIEZ, E., La formación del 
fundación de la Casa de España que por su infraestructura y prestigio ha sido una embajada oficiosa en la isla, por más que en largos periodos de tiempo premiara más el mero carácter lúdico ${ }^{42}$. De igual modo, es importante la fundación en San Juan de una filial de la Unión Ibero-Americana, asociación cuya central instituida en Madrid en 1885 mantenía relaciones con todas las repúblicas americanas mediante una cadena de filiales autónomas con claras pretensiones hispano-americanistas ${ }^{43}$.

El soporte publicístico de toda la colonia, y hasta cierto punto su guía cultural, era el Heraldo Español, que había reaparecido el 30 de enero de 1900, llevando entonces como subtítulo “España y los Pueblos Ibero-Americanos". Por más que el periódico tuviera como fin, al igual que otras muchas asociaciones españolas de la época, «la unión de todos los españoles [y] estrechar los lazos de amistad con puertorriqueños y norteamericanos", lo cierto es que desde un principio se opuso a la política asimilista oficial. Muy posiblemente sólo perseguía unos fines particulares, defendiendo intereses concretos españoles; pero el modo en que se hacía la defensa y, sobre todo, la circunstancia de estar defendiéndose del mismo ataque, hacía que crecieran las simpatías de los autonomistas hacia quienes un lustro antes eran sus mayores enemigos. El Heraldo respondía a esta inicial simpatía animando las demandas puertorriqueñas basadas en la herencia hispana. Tómese como ejemplo la utilización que se hace de las palabras de Castelar (tal vez el intelectual y político español más conocido y admirado en América a lo largo de la segunda parte del siglo $x(x)$, susceptibles de ser ratificadas por cualquier autonomista puertorriqueño en su lucha contra la americanización:

"Aunque no tuviéramos otra razón para creer en el espíritu nacional, tendriamos la razón del lenguaje. No podéis pensar ni emitir vuestro pensamiento, sino valiéndoos de la palabra. [...] Pongamos, sobre todo, la patria. Si te olvido, que pierda antes la memoria; si prefiero algo en el mundo a ti, que se me seque el corazón; si profano con malos pensamientos, con palabras indignas, tu armoniosa habla, que se me pegue la lengua al paladar, y que me muera mil veces si he de darte un solo dolor 0 de inferirte un agravio» ${ }^{44}$.

pueblo puertorriqueño. Contribución de catalanes, baleáricos y valencianos. San Juan, ICP, 1975; un segundo volumen estudia la aportación de gallegos y asturianos.

${ }^{42}$ Casa de España en Puerto Rico. San Juan, Tip. Negrón Flores, 1915. Zorrilla de San Martín, J. E., "La Casa de España", en Fernández Garcia, E., El Libro de Puerto Rico. San Juan, s.e., 1923, págs. 856-858.

${ }^{43}$ Reglamento de la Unión Ibero-Americana (Sociedad de Instrucción). Puerto Rico, Tip. del Heraldo Español, 1901. Sobre la asociación matriz, Sepúlveda MuÑoz, I., Unión Ibero-Americana (1885-1937), tesis de licenciatura, UNED, 1989, y «Medio Siglo de asociacionismo americanista español, 1885-1936", en Espacio, Tiempo y Forma, serie V. 4; Madrid, 1991; págs. 271-290.

${ }^{44}$ Castelar, E., "La Patria", Heraldo Español, 7 de octubre de 1900, pág. 2. 
Animados por semejantes sentimientos fueron apareciendo a lo largo de las dos primeras décadas de siglo una serie de obras que, defendiendo la continuidad cultural mantenida por la tradición, combatían la política asimilista estadounidense. Este es el caso del ensayo de Manuel Fernández Juncos, La lengua castellana: Su importancia y utilidad en Puerto Rico, donde ya mantiene el argumento de hacer consustanciales la lengua y la identidad nacional. Al hablar de castellano y no de español trata de desnacionalizar el idioma, desvinculándolo explícitamente del sistema político anterior y examinando el hecho concreto de la realidad nacional puertorriqueña. En el fondo se encuentra en la línea de los apologistas de los "idiomas nacionales" y dentro de la polémica que se estableció en el Cono Sur en los años treinta a cincuenta del siglo XIX; aunque conociendo el resultado final de aquel debate se abstiene de llamar a la lengua "puertorriqueña», retomando la idea de tener a la España-Castilla del Siglo de Oro como origen de las repúblicas americanas y de la misma España contemporánea ${ }^{45}$.

Más evidente es la defensa del pasado español de la isla es la obra de Cristóbal Real, La ominosa España; que no es otra cosa que la defensa de la política española en Puerto Rico ante la campaña de sistemático descrédito de todo el pasado que las autoridades estadounidense llevaban a cabo en la época ${ }^{46}$.

Semejantes ideas y motivada por la misma causa es la obra de Elpidio de Mier, Pensando en España. Su aportación más significativa es la identificación del pasado bajo administración española como fundamento de la nación puertorriqueña; en consecuencia, el ejemplo no ha de buscarse en la fuerza de ocupación sino en la Península. Igualmente contundente era su ataque a lo que calificaba como «agentes del yanqui en Hispanoamérica", que a diferencia de otros países americanos habian entrado en Puerto Rico brusca y favorablemente tras la ocupación; los más influyentes de agentes eran las sociedades de los rotarios, la YMCA y las iglesias protestantes ${ }^{47}$.

${ }^{45}$ Fernández Juncos, M., La lengua castellana: Su importancia y utilidad en Puerto Rico. San Juan, Imp. El País, 1903.

${ }^{46}$ Real, C., La ominosa España. Puerto Rico, Tip. del Boletín Mercantil, 1905. Una obra de fondo semejante, CANAL, E., Por España antes que por mi. Una polémica inconveniente y necia. San Juan, Tip. Catholic Trade School, 1915.

${ }^{47}$ DE MIER, E., Pensando en España. Ponce, Imp. Baldorioty, 1906. Sobre la importancia de las iglesias protestantes en la labor de sajonización, SiLva Gotay, S., "La iglesia protestante como agente de americanización en Puerto Rico: 1898-1917", Anales del Caribe 1984-1985, núms. 4-5, págs. 36-69. VARGAS RIVERA, R., «La Iglesia protestante y la americanización de Puerto Rico», El Cuervo, julio-diciembre de 1989, núm. 2, págs. 30-37. 
Durante el primer tercio de siglo destacaron dos personajes, de importancia decisiva en los panoramas político e intelectual de Puerto Rico: José de Diego y Cayetano Coll Cuchí. Éste fue delegado para representar a Puerto Rico en la celebración del centenario de las Cortes de Cádiz. En su discurso aparece la idea de la defensa de la personalidad puertorriqueña mediante su vinculación al mundo hispanoamericano; tendencia que no haría otra cosa que acrecentarse con el tiempo y tuvo en los años treinta y sesenta-setenta su mayor aceptación. El punto de vista de Coll Cuchí, y con él el de buena parte de los dirigentes autonomistas, se encontraba motivado por la práctica de Estados Unidos de una política exterior muy agresiva, especialmente en el ámbito caribeño; se consideraba que Puerto Rico era una más (de hecho, la primera) de las víctimas de la política del big stike; por esto se criticaba amargamente el militarismo estadounidense $y$, como denunciara posteriormente, de sus dos hijos: "el imperialismo en el exterior, y el despotismo en el interior" ${ }^{48}$. La acción más eficaz para contrarrestar esta política aconsejaba ser la ruptura de los planteamientos de la Unión Panamericana y la formalización de la unión de los paises hispanoamericanos. Lo que se encontraba de acuerdo con el surgente movimiento hispanoamericanista que tanto en España como en las repúblicas americanas se veía potenciado por causas muy diversas, desde el descontento ante la política estadounidense o la crisis del positivismo, hasta la ola de inmigración masiva ${ }^{49}$.

Puerto Rico encuentra de este modo un marco de referencia acorde a sus propósitos y siguiendo unas características que, aunque se han modificado en su apariencia exterior, se han mantenido intangibles a lo largo del presente siglo; estas son la pertenencia al ámbito político y económico estadounidense y al ámbito social y cultural latinoamericano. Las repetidas llamadas de Coll Cuchi (hay que remontarse hasta Hostos para encontrar su origen) para testimoniar la pertenencia de Puerto Rico a un mundo hispanoamericano más unido, deben interpretarse como un medio para defender la personalidad nacional puertorriqueña, que por causas insoslables debía mantenerse dentro del ámbito estadounidense.

Este argumento no es aplicable, sin embargo, a los planteamientos latinoamericanos de los independentistas, especialmente cuando provienen de posicionamientos socialistas o comunistas, desde Albizu Campos

${ }^{48}$ Coll CuCHI, C., Orientación política de América. Nueva York, Laisne \& Rossboro inc., 1928; el texto reproduce una conferencia pronunciada en la Universidad de Columbia ( 1 de febrero de 1928), invitado por Federico de Onís.

${ }^{49}$ Sepulveda Muñoz, I.: Comunidad cultural e hispano-americanismo 1898-1936. Madrid, UNED, 1993. 
a José M. ${ }^{a}$ Bras; esta proyección latinoamericana tomó un ímpetu inesperado con la revolución cubana, ejemplo que sectores muy minoritarios pretendieron seguir buscando la consumación de la independencia ${ }^{50}$.

La figura de José de Diego también se encuentra claramente en esta doble línea de pertenencia cultural hispana y vinculación política y económica a Estados Unidos. Como el propio De Diego aseguraba, su

\begin{abstract}
"Campaña de amor por la supervivencia del alma ibérica en Puerto Rico no se revierte en una campaña de odio contra los Estados Unidos. Luchamos los puertorriqueños en la altura del ideal sin olvidar las cosas de abajo. [...] Puerto Rico asi debe ser y será un pueblo independiente unido a España por un amor filial, a las Repúblicas iberas por un amor fraternal y a los Estados Unidos por un amor de conveniencias ${ }^{51}$.
\end{abstract}

Dado que la pertenencia política al marco estadounidense estaba asegurada por la presencia militar en la isla y la entrada en vigor de las Leyes Foraker y Jones, ésta con la concesión de una ciudadanía estadounidense, el mayor esfuerzo acometido fue asegurar la pertenencia de Puerto Rico al ámbito cultural americano. Esto se procuraba no por un afecto a los lazos de "raza o sangre", de los que se pueden encontrar abundantes ejemplos contrapuestos, desde muestras de solidaridad a evidentes prácticas segregacionistas. La aproximación de Puerto Rico al mundo americano se produce como respuesta a la política de asimilación y ante el temor a que una pérdida de identidad nacional conlleve aparejado la anulación de la peculiaridad puertorriqueña dentro de la Unión. El hispanoamericanismo puertorriqueño era (y sin ánimo de extrapolar, lo es en la actualidad) utilizado como instrumento defensivo contra la "yanquización" de la isla. Esto se pone de manifiesto cuando se estudian sus ideas en el discurso pronunciado en la celebración del Día de Colón (fiesta oficial en Puerto Rico desde 1913, año en el que la Unión Ibero-Americana había lanzado la idea, y muchas repúblicas la siguieron con los años, de la celebración conjunta de la Fiesta de la Raza el 12 de octubre). Señala la amenaza que para toda América supone la política estadounidense, contra la que no encuentra más adecuada respuesta que la unión de las repúblicas de cultura hispana:

${ }^{50}$ Sobre la diferencia radical en la interpretación de la personalidad puertorriqueña y su trasposición políticas, es ejemplar la obra de un militante del PPD que considera enemigos de Puerto Rico por igual a comunistas, anexionistas e independentistas; Cardona Cartagena, 1., Conozca los enemigos del Pueblo puertorriqueño. Río Piedras, Ed. Diálogo Nacional, 1979.

5) De Diego, J., Nuevas Campañas, op. cit., págs. 339-340. 
«En mi angustiosa peregrinación, voy defendiendo, con la emancipación de mi patria, la hermandad de los pueblos iberos y llevo siempre en los ojos y en la mente la visión de la libertad puertorriqueña y el triunfo del alma española en la hegemonía y el progreso del mundo" ${ }^{52}$.

De Diego comprendió que nada mejor podía ayudar a mantener este status que la defensa de la preeminencia del español. Por ello se opuso resueltamente a la política educativa que a partir de 1913 alcanzaba su máxima expresión para la eliminación de la enseñanza en español. De Diego presentó ante la Cámara legislativa un proyecto «Para el mejoramiento de la enseñanza pública en el lenguaje castellano, y la perfecta enseñanza del inglés en Puerto Rico", que en su artículo primero reclamaba también la derogación de la Ley de Idiomas Oficiales. La campaña emprendida para la aprobación de la ley y el ambiente creado anteriormente por la Asociación de Maestros alcanzaron una gran resonancia en toda la isla. Las autoridades estadounidenses se opusieron resueltamente al proyecto y desataron una contraofensiva en la que no faltaron las represalias contra aquellos que públicamente colaboran con De Diego. Se llegó a decretar la expulsión de alumnos de la Escuela Central por el mero hecho de recoger firmas a favor del proyecto; estas expulsiones y los despidos de maestros dieron origen a la creación del Instituto $\mathrm{De}$ Diego ${ }^{53}$. Finalmente el proyecto, tras una vehemente defensa de su autor fue aprobado por la Cámara (4 de marzo de 1915), pero el Consejo Ejecutivo lo vetó, no alcanzando nunca el rango de ley.

Las expectativas de De Diego fueron a partir de entonces por un camino más amplio. Recuperó la ya casi centenaria idea de la unión de las islas antillanas en una entidad política federal ${ }^{54}$. En los momentos más duros de las intervenciones estadounidenses en el Caribe, propugnó la fundación de la Unión Antillana, en la que en principio estarían integradas Cuba, la República Dominicana y Puerto Rico, con previsión para la incorporación de Haití. La defensa de esta unión política y la del idioma la supo fundir con la creación de la Academia Antillana de la Lengua, cuya principal misión era la defensa del español en el ámbito caribeño.

52 De Diego, J., «Puerto Rico en el problema de la raza»; rep. en Nuevas Campañas, op. cit., pág. 345.

53 Delgado Citrón, C., "La polémica del idioma y la creación del Instituto De Diego", RCAPR 38, noviembre de 1977, pág. 565.

${ }^{54}$ La idea provenía de los primeros intentos independentistas de las colonias caribeñas en la tercera década del siglo $x \mid x$; fueron revitalizadas por los independentistas cubanos y puertorriqueños en el último tercio de siglo. Ya en el xx su formulación se presenta en Gouin $C_{A}$. SANOVA, F., Las Grandes Antillas y la presión yankee. San Juan, Tip. Boada, 1916. 
Un ejemplo paradigmático del intento de utilización de la vinculación a la América hispana frente a Estados Unidos fue la obra de Rosendo Matienzo Cintrón, que aprovechaba la peculiar situación puertorriqueña para instrumentalizarla como política exterior y elevarla a la categoría de cualidad nacional. Nace así la idea de un Puerto Rico como puente entre la América sajona y la hispana. En entrevista al Heraldo Español, Matienzo definía esta posición:

«Seremos los intérpretes del puro pensamiento anglosajón entre nuestros hermanos, cuando los estados del norte, depuradas sus intenciones de insensatas codicias, no quieran tener con nosotros los iberoamericanos otras relaciones que las de una sincera y leal amistad, que las de un compañerismo confiado y sin pretensiones absurdas» ${ }^{55}$.

Una de las aportaciones más ambiciosas de Matienzo fue la creación de "Pancho Ibero", personaje que según su autor venía a representar la cultura y la raza iberoamericana, como John Bull lo hacía con Inglaterra y Uncle Sam simbolizaba los Estados Unidos. A diferencia de otros intelectuales de la época, no abogaba por un enfrentamiento entre las culturas y sus políticas y economías, sino que mantenía una voluntad bondadosa y bienintencionada, que pretendiéndose alejarse de aquélla en no pocas ocasiones cae en el idealismo y la ingenuidad ${ }^{56}$. No por ello dejó de tener una amplia repercusión en el ambiente intelectual de Puerto Rico, aunque no ocurriera lo mismo en el resto del continente americano.

La profesora Silvia Aguiló, en su magnífico estudio sobre el movimiento cultural puertorriqueño que aquí se sigue, pospone hasta la década de los veinte la utilización común de la denominación de la relación puertorriqueña entre ambas Américas como "puente entre dos culturas". EI primer autor que explícitamente denomina así el proyecto que debería llevar a cabo Puerto Rico fue Claudio Capó:

"Veo a mi patria cumpliendo su providencial misión, como uno de los pueblos privilegiados de América [...] sirviendo de puente espiritual entre las dos grandes familias del hemisferio; llevando la paz y el amor entre

\footnotetext{
${ }^{55}$ Rep. en Diaz Soler, L. M., Rosendo Matienzo Cintrón: Orientador y guardián de una cultura. Río Piedras, Ed. Instituto de Literatura Puertorriqueña, 1960, t. 1, pág. 552. Un segundo volumen presenta una recopilación de su obra.

56 Matienzo Citrón, R., "Pancho Ibero", La Correspondencia de Puerto Rico, 5 de enero de 1911, pág. 4. Sobre la importancia de su creación en Puerto Rico vid. LLORENS TORRES, L, "Matienzo: Su inmortal creación de "Pancho Ibero" como tipo representativo de Hispanoamérica", Revista de las Antilias, 1914, vol. II, núm. 1.
} 
angloamericanos e iberoamericanos de buena fe, de recto corazón y de firme voluntad" ${ }^{57}$.

No sólo autores puertorriqueños consideraban idóneo para la potenciación cultural de la isla quedar constituida en una encrucijada de culturas. Éste fue el planteamiento de Bailey K. Ashford, que escribía un artículo titulado precisamente "The Bridge between the Americas» ${ }^{58}$.

Esta idea ya está presente en el ánimo que llevó a la fundación de una de las revistas literaria americana más prestigiosas de la segunda década de siglo, la Revista de las Antillas. A pesar de su escasa permanencia (dos años, catorce números) supo reunir un buen conjunto de colaboradores, entre los que destacaron Muñoz Rivera, Coll Cuchí, De Diego, Nemesio Canales, Epifanio Fernández Vanga, Mariano Abril, Martín Travieso, Luis Bonafoux, etc. La dirigió durante toda su existencia Luis Llorens Torres, quien en el artículo que presenta la revista manifestaba con claridad el sentido de encrucijada que la cultura puertorriqueña quería presentar ante el resto de América; la defensa del idima era, como durante todo el período, la bandera simbólica de identidad y vinculación:

"España y los pueblos hispanos de América suman una totalidad de cien millones de habitantes que hablan la misma lengua, la gloriosa lengua castellana. Espan̄a, al confín del Atlántico; Filipinas, al confín el Pacífico; América entre ambos océanos: he aquí el gran escenario de nuestro idioma. [...] La Revista de las Antillas aspira a ser un palenque más de nuestra cultura y de nuestra raza, un estimulo de lucha y progreso y un vínculo de fraternidad hispano-americana» ${ }^{59}$.

Este panorama de las dos primeras décadas de siglo sufrió una paulatina modificación en los años veinte, si bien no por ello se dejaron de mantener los presupuestos anteriores. Este cambio se vincula a la desilusión por la cultura europea que sufre la intelectualidad americana tras la guerra mundial. Enterrado definitivamente el positivismo, los autores se vuelven hacia lo autóctono y al racionalismo universalista contraponen el arcaísmo explícito en lo telúrico de cada particularidad nacional. Parte de este movimiento tendió al establecimiento de macroestructuras continen-

57 CAPÓ, C. "Consideraciones en torno a la integración económica", en FERNÁNDEZ MÉNDEZ, E. (ed.), Antología del pensamiento puertorriqueño. Barcelona, Ed. Universitaria, 1975, t. 1, pág. 225

s8 AshFORD, B. K., "The Bridge between the Americas", North American Review, septiembre de 1924, vol. 220, núm. 50, pág. 47 en Aguiló, S., op. cit., págs. 136-137.

59 Llorens Torres, L., Revista de las Antillas, marzo de 1913, núm. 1, pág. 1. 
talistas de clara raigambre hispano-americanista, como José Vasconcelos con su Indología y Raza Cósmica, o Ricardo Rojas con Indoamérica. Otra parte de esa exaltación de lo propio estuvo dirigida hacia la definición de los rasgos particulares, y por ello diferenciadores, de cada uno de los grupos americanos y de su esencia particular. Los resultados fueron muy variados, desde las denuncias de discriminación racial a la concienciación proletaria (urbana y rural), desde la crítica a los débiles sentimientos y bases nacionales en toda América, a la exaltación de la patria como entidad suprahistórica. En esta línea cabe encuadrar aportaciones tan variadas como ¿A dónde va Indoamérica? de Haya de la Torre, Siete ensayos de interpretación de la realidad peruana de Mariátegui, Radiografía de la Pampa de Martínez Estrada, o Perfil del hombre y la cultura en México de Samuel Ramos. En Puerto Rico este retorno al particularismo profundo del pueblo tiene su manifestación en la publicación de una serie de revistas (Is/a, Brújula y especialmente a partir de 1929 la revista índice), y las obras de Antonio S. Pedreira, Insularismo, y de Tomás Blanco, Prontuario Histórico.

En la Universidad de Puerto Rico se crea en 1927 el Departamento de Estudios Hispánicos, que desde un principio desarrolló una gran labor de investigación; a él estuvieron vinculados los profesores Tomás Navarro Tomás, Federico de Onís y Ángel del Río (pasaron por sus aulas Américo Castro, Ángel Valbuena Prat o Fernando de los Ríos) y a su alrededor se desarrolló una fundamental labor creativa que dio origen a la conocida como "generación del treinta". La revista índice no suscitó el nacimiento de una nueva generación cultural, pero tuvo el mérito de reunirla y darle un mínimo común denominador. Creada por Pedreira, Collado Martell, Samuel Quiñones y Vicente Géigel Polanco, pronto reunió en su colaboración a las más importantes firmas del panorama intelectual puertorriqueño. La aparición el 23 de abril de su primer número no fue en absoluto una casualidad, lo que manifestaba desde su inicio su voluntad combativa en la constante batalla del idioma. Para manifestarlo claramente, se propicia una encuesta en cuya presentación se mezcla la identidad culturalista de la publicación, al tiempo que su preocupación política y social, tratando de definir por inducción la personalidad del pueblo puertorriqueño:

"Sobre el panorama confuso de nuestra cultura, aalndice señala hoy la sonrisa de la esfinge patria, [...] y sin rodeos eufemistas, planteamos el problema: ¿Qué somos y cómo somos?" ${ }^{60}$.

${ }^{60}$ "Nuestra encuesta", índice, 13 de mayo de 1929, núm. 2, pág. 17. La encuesta recogió la 
Quien con más profundidad e influencia posterior contestó a esa pregunta fue el profesor del Departamento de Estudios Hispánicos, Antonio Pedreira, que con Insularismo desempeñó el papel definidor de la personalidad histórica puertorriqueña que en España tuvo la polémica entre Claudio Sánchez Albornoz y Américo Castro. Para Pedreira Puerto Rico es algo por hacer, inacabado, pero por su potencialidad y la realidad presente, una entidad individual e independiente. Los valores y tradiciones, el idioma y la historia son las bases constitutivas de la peculiaridad. Su generación era la primera que podía afirmarlo de un modo sereno y reflexivo: durante el siglo XIX la circunstancia colonial impedía que se viera en la tradición hispana nada más que la manifestación de dominio metropolitano; en las primeras décadas del XX por contra el pueblo y sus representantes se habían aferrado a ello frente a de la política de asimilación. Sólo en los años treinta podía apreciarse claramente la importancia que su continuidad tenía para acabar de edificar la personalidad puertorriqueña. Para ello el idioma era fundamental:

«El lenguaje es como un arca depositaria de la substantividad de un pueblo. [...] Y es que cada pueblo lleva en su lengua el alma de su raza y el espíritu de su región. En el rico pentagrama de la lengua española Puerto Rico tiene también su nota. [...] Como todos los pueblos hispanoamericanos poseemos también un matiz que no procede de la importación sino que nació enraizado en nuestro suelo moral saturado espontáneamente de los rasgos típicos de nuestro carácter ${ }^{61}$.

A la anterior lista de autores literarios y ensayistas, obligadamente comprimida y recortada, se deben añadir un largo número de intelectuales y políticos que desde los años cuarenta han mantenido viva la llama de la identidad cultural puertorriqueña, en la mayoría de los casos utilizándolos como instrumento principal en su movimiento de reivindicación nacional. Luis Muñoz Souffront, Francisco Vincenty, Alfonso L. Garcia Martínez, José Ferrer Canales, Rafael Arjona, Awilda Palau o Pedro Juan Rua ha sido algunos de estos significados defensores de la lengua como palanca de identificación nacional.

\section{LA COYUNTURA PRESENTE}

La última etapa de esta batalla del idioma se ha desarrollado en los últimos años. De igual modo que en 1902, 1917 y 1948, está estrecha-

respuesta a la pregunta de numerosos integrantes de esta generación; sus palabras fueron publicadas a lo largo de los números aparecidos en el año 1929

${ }^{61}$ Pedreira, A. S., Insularismo. Río Piedras, Edil, 1973, págs. 139-140. 
mente relacionada con la política exterior estadounidense y el status constitucional de Puerto Rico. Tiene una gran importancia política, aunque su trascendencia social hasta ahora había sido menor que la de las campañas anteriores; abarca diversos campos, especialmente el jurídico, legislativo y en menor medida el educativo. Es en si una campaña para erradicar el bilingüismo obligatorio y hacer del español el único idioma oficial, deponiendo la Ley de Idiomas Oficiales de 1902; se encuentra en explícita y abierta oposición a la campaña de origen continental que propone la obligatoriedad del inglés en todo el territorio estadounidense, movimiento conocido por english only ${ }^{62}$. En respuesta, y con una clara motivación política, surgió la Acción Nacional para la Defensa del Vernáculo, cuyo fin es «impulsar activamente la afirmación del vernáculo español en las esferas gubernamentales, educativas, sociales y jurídicas de nuestro país" ${ }^{63}$.

Este movimiento culminó el 5 de abril de 1991 con la firma por Hernández Colón de la Ley número 4 que declaraba como único idioma oficial de Puerto Rico el español, derogando la Ley de Idiomas Oficiales de 1902. Escasos meses después el gobernador recibía de manos de don Felipe de Borbón el premio Príncipe de Asturias, concedido «al pueblo de Puerto Rico por su defensa del español».

En las elecciones del 3 de noviembre de 1992 el panorama político puertorriqueño dio un vuelco significativo. Pedro Rosselló supo aprovechar la división interna del PPD y las críticas al largo gobierno de Hernández Colón para sumar más de 900.000 votos y conseguir mayoría absoluta en las dos Cámaras legislativas. El objetivo explícito de Rosselló es integrar definitiva y totalmente a Puerto Rico en Estados Unidos. El idioma es de nuevo un símbolo y una herramienta. Desde la perspectiva del PNP sería un despropósito intentar presentar en Washington la propuesta de ser admitidos como el cincuenta y un estado de la Unión sin poder pre-

${ }^{62}$ Lo promueve la asociación "U. S. English», fundada en 1982 por el senador Sesue I. Ha. yakawa, lingüista de ascendencia japonesa. En su paso por el Senado, Hayakawa presentó en abril de 1982 un proyecto de enmienda a la constitución estadounidense: «El idioma inglés será el idioma oficial de los Estados Unidos. Ni los Estados Unidos ni ningún estado aprobará ley alguna que requiera el uso de otro idioma que no sea el inglés". Con el mismo origen, en febrero de 1993 fue presentado un nuevo proyecto de enmienda similar.

${ }^{63}$ Acción Nacional fue fundada el 20 de mayo de 1987 en la Facultad de Derecho de la Universidad de Puerto Rico, recinto de Río Piedras, presidida por Pedro Juan Rúa. Dos años después se instituyó el "Día Nacional del Idioma Español», celebrándose en todo Puerto Rico el 16 de abril, aniversario de José de Diego; vid. DeLGADo Citrón, C., art. cit., págs. 4-5. "Special day reafirm Spanish language», The San Juan Star, 17 de abril de 1989, pág. 3. “Frente amplio para la defensa del idioma español», El Mundo 17 de abril de 1989, pág. 4. 
sentar los documentos oficiales en inglés. Las ya profundas reticencias de las Cámaras legislativas estadounidenses sobre la conveniencia de aceptar la anexión de la isla se ampliaría por el hecho de que Puerto Rico sería el primer estado no anglófono de la Unión. Hay otro motivo más inminente: más del 80 por 100 de la economía puertorriqueña es dependiente de Estados Unidos; los círculos empresariales habían apostado fuerte por Rosselló y su primera exigencia fue poder utilizar de nuevo el inglés como lengua oficial.

La hora presente es para Puerto Rico la de la decisión. Ante ella caben tres posibilidades. La primera, más sencilla pero imposible de sostener a largo plazo, es el mantenimiento del ELA, recibiendo el estado los casi 8 mil millones de dólares anuales de los fondos federales y los particulares sus cheques de beneficencia mensuales. La segunda opción es la evolución del ELA hasta conseguir hacer más laxos los lazos con Washington e incluso llegar a la independencia total, recibiendo las contraprestaciones por las abundantes bases militares estadounidenses (el 15 por $100 \mathrm{del}$ territorio puertorriqueño) y los impuestos por el comercio internacional. La tercera es la anexión como cincuenta y un estado de la Unión, lo que conllevaría el aumento de los subsidios federales y la facilidad (ya muy amplia) para la inversión continental.

Tras estas posibilidades se encuentran dos posturas irreconciliables, pues responden a dos concepciones de la identidad puertorriqueña totalmente contrapuestas. Para unos Puerto Rico es un pueblo que, como nación, tiene derecho a constituirse como estado independiente. Para otros es ya parte de Estados Unidos, como una minoría más de las que compusieron su crecimiento y sobreviven en su interior. Para ambos el idioma es el símbolo:

«La cultura puertorriqueña de la cual nuestra lengua es la más preciada seña de identidad, es una fuerza irreductible. La vigencia del español es consustancial con nuestra existencia misma como pueblo. Sangre de nuestro espíritu como dijo Unamuno, sin la lengua no habría patria" ${ }^{64}$.

El nuevo Gobernador Rosselló, en la firma de su polémica ley:

"Dos banderas, dos himnos, dos idiomas. Reflejos preciosos de una ciudadanía que atesoramos y de una realidad de pueblo que valoramos» ${ }^{65}$.

\footnotetext{
64 Hernández Colon, R., "El inglés y el anexionismo puertorriqueño», $A B C, 31$ de enero de 1993, pág. 76 .

${ }^{65}$ Rep. en Semprún, A., "Puerto Rico, la batalla del español», Ibidem, pág. 75.
} 
En ambos frentes el idioma es el símbolo de su identidad; exclusiva la primera, integrada la segunda. Para ambos es instrumento de ligazón a distinto orbe cultural: iberoamericano y estadounidense respectivamente. Esta escisión es un corte transversal a la ciudadanía de Puerto Rico; alcanza los más abstractos conceptos, como el de nación, y los más pedestres e irrenunciables medios de participación social.

Dos ejemplos de esto son altamente significativos, al tocar los más altos símbolos de la soberanía de un estado: mientras una minoría celebra el 4 de julio con sinceras lágrimas ante el izado de la bandera estadounidense (no en vano un considerable número ha servido e incluso ha perdido algún ser querido en la defensa de esa misma bandera), una buena parte de puertorriqueños denominan la insignia estadounidense «la pecosa", por el contraste entre sus cincuenta pequeñas estrellas y la gran estrella solitaria de la bandera de Puerto Rico. El segundo caso alcanza la más significativa simbología, pues muestra la negación radical de la más ordinaria realidad: cash o el doble sistema monetario puertorriqueño. En la publicidad, en un mercadillo rural, en cualquier tienda no exclusiva de turistas los precios, a pesar de ser anunciados con el símbolo del dólar $\$$, son enunciados por vendedores y compradores en un desconcertante sistema monetario paralelo de monedas hispanas; lo que de California a Maine es un dólar, en Puerto Rico es un peso; 25 centavos - quartedson un duro; 10 centavos - dime - son una peseta; la moneda de cobre de un centavo - cent- es conocida por chavo.

Como se ha expuesto en las páginas anteriores, el enfrentamiento entre los dos sectores se ha mantenido a lo largo del presente siglo y ha tenido su evolución coincidiendo con cambios en el status constitucional. El momento presente es un impasse — motivado por el agotamiento del ELAcuya dirección de salida está en juego. Anexionistas y contraanexionistas tratan de llevar a cabo el paso definitivo. En conclusión, en qué idioma debe estar redactada la pregunta que contenga la papeleta del próximo referéndum.

\section{UNA VISIÓN DESDE ESPAÑA}

Para España la duda existencial puertorriqueña tiene especial interés. No por que los caribeños hablen una lengua que consideramos nuestra, desde una miopia heredada secularmente; dado que no ya en las postrimerías del siglo $x x$, sino desde hace casi dos siglos, el idioma español pertenece en la misma medida a España como a cada uno de los países de la comunidad hispanohablante, desde México a Chile. 
El problema idiomático interesa a España por dos razones muy distintas. En primer lugar al haber sido implicada por los contendientes en esta lucha por la identidad. Los estadistas o anexionistas, que criticaron la concesión del Premio Príncipe de Asturias como una ingerencia española, han sostenido un discurso en el que se vertían los más negros juicios sobre España, llegando, en ios extremos de su ataque al contrario, al desprecio más ordinario. Por su parte, los libreestadistas e independentistas sostienen una suerte de amor y odio - por otro lado tan presente en el resto de Iberoamérica - hacia España; se resucita la acusación de exterminio del aborigen (taínos), como secuela del discurso independentista de finales del siglo $\mathrm{xIX}$, remozado posteriormente con un indigenismo que -en una paradoja sólo aparente - tuvo sus principales sostenedores en las filas anexionistas; pero al mismo tiempo se mantiene posturas de un cariño tan "filial" como la manifestada por el líder independentista y socialista Rubén Berrios. En el discurso que cerraba la gran marcha de protesta por él convocada, su frase más significativa fue: «Puerto Rico, como la Madre Patria y el resto de la comunidad iberoamericana, quiere hablar español.» A nadie escapó la satisfacción con que Hernández Colón recibió el Príncipe de Asturias y fue invitado con posterioridad a la celebración de la I Cumbre Iberoamericana en Guadalajara; de igual modo, apostó fuerte por la representación de Puerto Rico en la Exposición Universal de Sevilla, levantando un magnífico pabellón que por su elevado costo concitó las críticas en la isla, incluso entre sus partidarios.

Si bien no de modo principal, España ha sido incluida en el discurso sobre la identidad puertorriqueña. Pero la misma España tiene algo que aprender y algo que enseñar en este enfrentamiento. Si bien no el único, sí es el país de la comunidad iberoamericana donde más lenguas se hablan, alcanzando su oficialidad al estar reconocidas y amparadas por la Constitución ${ }^{66}$. La diversidad idiomática, el respeto por las minorías lingüísticas, no conlleva división sino riqueza cultural. Esto es algo que deberían tener en cuenta los dos bandos puertorriqueños: los contrarios a la oficialidad del inglés, argumentando que no alcanza un 20 por 100 del total la población que puede hablar inglés; y los anexionistas, deseosos de establecer una identidad que los hermane con "lllinois o Arkansas", en expresiva frase de un periodista de la isla. Al mismo tiempo España

66 Ya lo señaló hace años el actual Gobernador Pedro Rossello - con un asomo de cínico oportunismo-- para respaldar su tesis de la doble oficialidad: "Vemos naciones donde hay iguałdad legal de más de un lenguage [...] La madre patria, España, es ejemplo de un lenguaje oficial conviviendo con múltiples idiomas regionales». RosselLo. P. J., "El mito del idioma", El Nuevo Día, 1 de mayo de 1989, pág. 45. 
tiene algo que aprender de esta cerrada disputa: la firmeza y resolución en la defensa del propio patrimonio cultural y la identidad nacional. En las páginas anteriores se ha tratado de hacer un somero análisis de la lucha que el pueblo de Puerto Rico ha llevado a cabo durante casi un siglo contra la pretensión estadounidense de asimilación cultural y anexión política; cuestionada primero y combatida después la primera, la anexión se vio imposible. También hace casi un siglo España comenzó a dudar de su propia existencia; en la actualidad, cuestionada interiormente por las identidades regionales y nacionalistas, y en el exterior por su integración en la Unión Europea, España debe volver a encontrar su propia identidad nacional (que nunca ha sido de exclusión, sino de agregación y participación diversa) para afrontar sus problemas de definición política. Para ello es más que aconsejable dirigir una mirada hacia Puerto Rico.

\section{POST-ESCRITUM}

Meses después de redactar el anterior artículo se ha celebrado el anunciado referéndum sobre el régimen político puertorriqueño (14 de noviembre de 1993). Los resultados han deparado una victoria mínima de las tesis del PPD apoyando la continuidad del ELA y negando la autorización al gobierno Roselló para solicitar ante Washington la admisión de Puerto Rico como $51 .{ }^{\circ}$ Estado de la Unión.

No es posible analizar aquí ni la significativa campaña electoral previa ni los resultados del referéndum. Sirvan cuatro ideas principales:

- A pesar de todo el despliegue publicitario (incluyendo mensajes de varios ex-presidentes de Estados Unidos) y de contar con el apoyo de la mayoría de los medios de comunicación, los partidarios de la anexión han quedado lejos de conseguir un resultado mayoritario $(46,2 \%)$, aunque han crecido considerablemente respecto al histórico referéndum de 1967 $(38,9 \%)$.

- La victoria ha correspondido a quienes explícitamente se opinían al ingreso de Puerto Rico en la Unión $(48,4 \%)$, pero era mayoritaria la opinión que solicitaba - aún apoyándolo- una reforma del ELA. El descenso respecto al plebiscito de 1967 ha sido notable $(60,41 \%)$.

- La opción independentista apenas ha sumado un 4\%; aspiraba a un $5 \%$, pero sobre todo a que ninguna de las otras opciones reuniera más del $50 \%$. Con lo cual las tres posiciones parecen haber ganado.

Para lo que realmente ha valido el referéndum ha sido para derrotar la aspiración de Roselló de solicitar el ingreso formal en Estados Unidos. 
El ELA no ha salido fortalecido y las negociaciones en Washington para su modificación serán poco menos que un despropósito: mientras Clinton apoyó - si bien tímidamente- el mantenimiento del ELA, Roselló difícilmente defenderá una ampliación de un Estatuto en el que explícitamente no cree. 